
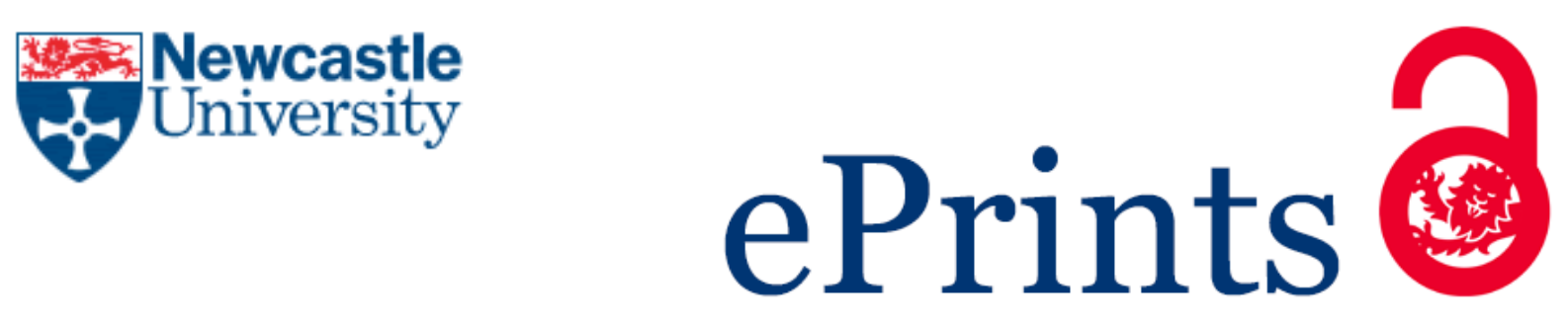

Josephson CB, White PM, Krishan A, Al-Shahi Salman R.

Computed tomography angiography or magnetic resonance angiography for detection of intracranial vascular malformations in patients with

intracerebral haemorrhage.

Cochrane Database of Systematic Reviews 2014, (9), CD009372.

Copyright:

(c) 2014 The Cochrane Collaboration. Published by John Wiley \& Sons, Ltd.

DOI link to article:

http://dx.doi.org/10.1002/14651858.CD009372.pub2

Date deposited:

$24 / 03 / 2016$ 


\section{Cochrane}

Cochrane Database of Systematic Reviews

\section{Computed tomography angiography or magnetic resonance angiography for detection of intracranial vascular malformations in patients with intracerebral haemorrhage (Review)}

Josephson CB, White PM, Krishan A, Al-Shahi Salman R

Josephson CB, White PM, Krishan A, Al-Shahi Salman R.

Computed tomography angiography or magnetic resonance angiography for detection of intracranial vascular malformations in patients with intracerebral haemorrhage.

Cochrane Database of Systematic Reviews 2014, Issue 9. Art. No.: CD009372.

DOI: 10.1002/14651858.CD009372.pub2.

www.cochranelibrary.com

Computed tomography angiography or magnetic resonance angiography for detection of intracranial vascular malformations in patients with intracerebral haemorrhage (Review)

Copyright @ 2014 The Cochrane Collaboration. Published by John Wiley \& Sons, Ltd. 
TABLE OF CONTENTS

HEADER . . . . . . . . . . . . . . . . . . . . . . . . . . . . . . . . . . . . . . . 1

ABSTRACT . . . . . . . . . . . . . . . . . . . . . . . . . . . . . . . . . . . . . . . . . . . . .

PLAIN LANGUAGE SUMMARY . . . . . . . . . . . . . . . . . . . . . . . . . . . . . . . . . . . . . . . . .

BACKGROUND . . . . . . . . . . . . . . . . . . . . . . . . . . . . . . . . . . . . . . .

OBJECTIVES . . . . . . . . . . . . . . . . . . . . . . . . . . . . . . . . . . . . . . . $4 \begin{gathered}4 \\ \text { O }\end{gathered}$

METHODS . . . . . . . . . . . . . . . . . . . . . . . . . . . . . . . . . . . . . . . .

RESULTS . . . . . . . . . . . . . . . . . . . . . . . . . . . . . . . . . . . . . . . 7

Figure 1. . . . . . . . . . . . . . . . . . . . . . . . . . . . . 8

Figure 2. . . . . . . . . . . . . . . . . . . . . . . . . . . . . . . . . . . . . .

Figure 3. . . . . . . . . . . . . . . . . . . . . . . . . . . . . . . . . . . . . . 14

Figure $4 . \quad$. . . . . . . . . . . . . . . . . . . . . . . . . . . . . . . . . . . . . 15

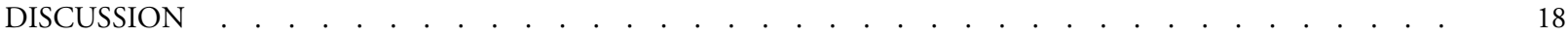

AUTHORS' CONCLUSIONS . . . . . . . . . . . . . . . . . . . . . . . . . . . . . . . . . . . . . . .

ACKNOWLEDGEMENTS . . . . . . . . . . . . . . . . . . . . . . . . . . . . . . . . . . . . . . . . 19

REFERENCES . . . . . . . . . . . . . . . . . . . . . . . . . . . . . . . . . . . . . . 20

CHARACTERISTICS OF STUDIES . . . . . . . . . . . . . . . . . . . . . . . . . . . . . . . . . . . 23

DATA . . . . . . . . . . . . . . . . . . . . . . . . . . . . . . . . . . . . . . . . 47

Test 1. CTA. . . . . . . . . . . . . . . . . . . . . . . . . . . . . . . . . . . . . 47

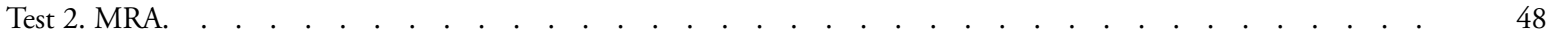

APPENDICES . . . . . . . . . . . . . . . . . . . . . . . . . . . . . . . . . . . . . 48

CONTRIBUTIONS OF AUTHORS . . . . . . . . . . . . . . . . . . . . . . . . . . . . . . . 52

DECLARATIONS OF INTEREST . . . . . . . . . . . . . . . . . . . . . . . . . . . . . . . . . . . . . . . . 52

SOURCES OF SUPPORT . . . . . . . . . . . . . . . . . . . . . . . . . . . . . . . . . . 53

DIFFERENCES BETWEEN PROTOCOL AND REVIEW . . . . . . . . . . . . . . . . . . . . . . 53

INDEX TERMS . . . . . . . . . . . . . . . . . . . . . . . . . . . . . . . . . . . . 53

Computed tomography angiography or magnetic resonance angiography for detection of intracranial vascular malformations in patients with intracerebral haemorrhage (Review)

Copyright $\odot 2014$ The Cochrane Collaboration. Published by John Wiley \& Sons, Ltd. 
[Diagnostic Test Accuracy Review]

\title{
Computed tomography angiography or magnetic resonance angiography for detection of intracranial vascular malformations in patients with intracerebral haemorrhage
}

\author{
Colin B Josephson ${ }^{1,2}$, Philip M White ${ }^{3}$, Ashma Krishan ${ }^{4}$, Rustam Al-Shahi Salman ${ }^{2}$ \\ ${ }^{1}$ Department of Clinical Neurosciences, University of Calgary, Calgary, Canada. ${ }^{2}$ Division of Clinical Neurosciences, University of \\ Edinburgh, Edinburgh, UK. ${ }^{3}$ Institute for Ageing and Health, Newcastle University, Newcastle Upon Tyne, UK. ${ }^{4}$ Edinburgh Clinical \\ Trials Unit, University of Edinburgh, Edinburgh, UK
}

Contact address: Colin B Josephson, Department of Clinical Neurosciences, University of Calgary, 12th Floor, Foothills Medical Centre, 1403-29 Street NW, Calgary, AB, T2N 2T9, Canada. colin.josephson@gmail.com.

Editorial group: Cochrane Stroke Group.

Publication status and date: New, published in Issue 9, 2014.

Review content assessed as up-to-date: 9 October 2013.

Citation: Josephson CB, White PM, Krishan A, Al-Shahi Salman R. Computed tomography angiography or magnetic resonance angiography for detection of intracranial vascular malformations in patients with intracerebral haemorrhage. Cochrane Database of Systematic Reviews 2014, Issue 9. Art. No.: CD009372. DOI: 10.1002/14651858.CD009372.pub2.

Copyright (C) 2014 The Cochrane Collaboration. Published by John Wiley \& Sons, Ltd.

\begin{abstract}
A B S T R A C T
Background

Intracranial vascular malformations (brain or pial/dural arteriovenous malformations/fistulae, and aneurysms) are the leading cause of intracerebral haemorrhage $(\mathrm{ICH})$ in young adults. Early identification of the intracranial vascular malformation may improve outcome if treatment can prevent ICH recurrence. Catheter intra-arterial digital subtraction angiography (IADSA) is considered the reference standard for the detection an intracranial vascular malformation as the cause of ICH. Computed tomography angiography (CTA) and magnetic resonance angiography (MRA) are less invasive than IADSA and may be as accurate for identifying some causes of ICH.
\end{abstract}

\section{Objectives}

To evaluate the diagnostic test accuracy of CTA and MRA versus IADSA for the detection of intracranial vascular malformations as a cause of $\mathrm{ICH}$.

\section{Search methods}

We searched MEDLINE (1948 to August 2013), EMBASE (1980 to August 2013), MEDION (August 2013), the Database of Abstracts of Reviews of Effects (DARE; August 2013), the Health Technology Assessment Database (HTA; August 2013), ClinicalTrials.gov (August 2013), and WHO ICTRP (International Clinical Trials Register Portfolio; August 2013). We also performed a cited reference search for forward tracking of relevant articles on Google Scholar (http://scholar.google.com/), screened bibliographies, and contacted authors to identify additional studies.

\section{Selection criteria}

We selected studies reporting data that could be used to construct contingency tables that compared CTA or MRA, or both, with IADSA in the same patients for the detection of intracranial vascular malformations following ICH.

Computed tomography angiography or magnetic resonance angiography for detection of intracranial vascular malformations in patients with intracerebral haemorrhage (Review)

Copyright $\odot 2014$ The Cochrane Collaboration. Published by John Wiley \& Sons, Ltd. 


\section{Data collection and analysis}

Two authors (CBJ and RA-SS) independently extracted data on study characteristics and measures of test accuracy. Two authors (CBJ and PMW) independently extracted data on test characteristics. We obtained data restricted to the subgroup undergoing IADSA in studies using multiple reference standards. We combined data using the bivariate model. We generated forest plots of the sensitivity and specificity of CTA and MRA and created a summary receiver operating characteristic plot.

\section{Main results}

Eleven studies ( $\mathrm{n}=927$ participants) met our inclusion criteria. Eight studies compared CTA with IADSA ( $\mathrm{n}=526)$ and three studies compared MRA with IADSA ( $\mathrm{n}=401)$. Methodological quality varied considerably among studies, with partial verification bias in $7 /$ $11(64 \%)$ and retrospective designs in 5/10 (50\%). In studies of CTA, the pooled estimate of sensitivity was 0.95 (95\% confidence interval (CI) 0.90 to 0.97 ) and specificity was 0.99 (95\% CI 0.95 to 1.00 ). The results remained robust in a sensitivity analysis in which only studies evaluating adult patients ( $\geq 16$ years of age) were included. In studies of MRA, the pooled estimate of sensitivity was 0.98 (95\% CI 0.80 to 1.00$)$ and specificity was 0.99 (95\% CI 0.97 to 1.00$)$. An indirect comparison of CTA and MRA using a bivariate model incorporating test type as one of the parameters failed to reveal a statistically significant difference in sensitivity or specificity between the two imaging modalities ( $\mathrm{P}$ value $=0.6$ ).

\section{Authors' conclusions}

CTA and MRA appear to have good sensitivity and specificity following ICH for the detection of intracranial vascular malformations, although several of the included studies had methodological shortcomings (retrospective designs and partial verification bias in particular) that may have increased apparent test accuracy.

\section{PLAIN LANGUAGE SUMMARY}

Computed tomography angiography or magnetic resonance angiography for detecting blood vessel abnormalities in patients with intracerebral haemorrhage

Blood vessel abnormalities are the leading cause of bleeding in the brain (known as intracerebral haemorrhage) in young adults. Early detection of blood vessel abnormalities may improve outcome if treatment can prevent bleeding recurrence. This review looked at different tests used to identify blood vessel abnormalities in the brain. Intra-arterial digital subtraction angiography (IADSA) is the standard test used and involves positioning a tube, introduced through a blood vessel in the groin, into blood vessels near the brain. Dye is directly injected into the brain's blood vessels using this tube. Computed tomographic angiography (CTA) and magnetic resonance angiography (MRA) are newer tests that may be done without any injections (MRA) or only through an injection into the arm (CTA and MRA). This review investigated the accuracy of CTA or MRA, or both, compared with IADSA after intracerebral haemorrhage. We found eight studies (involving 526 participants) that compared CTA with IADSA and three studies (involving 401 participants) that compared MRA with IADSA. Both CTA and MRA appear to have good accuracy when compared with IADSA. However, the studies were small and were limited in many cases by their design. Further research that looks at accuracy, practicality, and costs is needed.

\section{B A C K G R O U N D}

A stroke is a clinical syndrome characterised by a sudden loss of focal brain function causing symptoms that last more than 24 hours or lead to death. Strokes occur either because of inadequate blood supply to the brain (ischaemic stroke) or because of bleeding. Bleeding can be between the membranous layers that surround the brain or into the ventricles of the brain. However, bleeding directly into the brain substance (intracerebral haemorrhage or $\mathrm{ICH})$ is a particularly devastating form of stroke. It accounts for $10 \%$ to $15 \%$ of all strokes in Caucasian populations (Lovelock 2007) and the one-month case fatality is approximately $40 \%$ (Van Asch 2010). 
It is extremely important to make the distinction between ICH and other forms of stroke since the causes, prognosis, and treatment vary according to each condition. No clinical scoring systems have yet been shown to be accurate in distinguishing between these entities. Therefore, timely brain imaging is required to differentiate ICH from ischaemic stroke and the other forms of haemorrhagic stroke (Al-Shahi Salman 2009). Computed tomography (CT) and magnetic resonance imaging (MRI) have both been used in clinical practice. A Cochrane review of diagnostic test accuracy has confirmed the utility of CT for detecting acute haemorrhagic stroke but has concluded that insufficient information exists to establish the merits of MRI for this purpose (Brazzelli 2009).

If a scan demonstrates $\mathrm{ICH}$, the priority shifts to investigating the cause of the bleed in order to estimate prognosis and direct treatment. Physicians tend to infer the cause of $\mathrm{ICH}$ on the basis of the patient's age, co-morbidities, and ICH characteristics on CT or MRI. For instance, elderly patients with preceding hypertension and ICH in a 'deep' location in the brain are often assumed to have had a bleed unrelated to any underlying structural abnormality, while young patients with 'deep' ICH and no past history of high blood pressure are often investigated for an underlying vascular malformation (Cordonnier 2010). However, these assumptions may be inaccurate (Cordonnier 2010). Additional history, laboratory investigations, and sophisticated radiological tests may help to establish the cause of ICH.

\section{Target condition being diagnosed}

Intracranial vascular malformations are of particular importance as they are the leading cause of ICH in young adults (explaining as many as one-third of cases in young people; Al-Shahi 2001) and cause an appreciable proportion of $\mathrm{ICH}$ in older people $(18 \%$ (95\% CI $13 \%$ to $24 \%$ ) of cases in people aged $\geq 50$ in a recent systematic review; Cordonnier 2010). Intracranial vascular malformations include arteriovenous malformations, dural arteriovenous fistulae, and aneurysms (which are the target conditions in this review). Arteriovenous malformations are abnormal tangles of dilated arteries and veins of varying calibre that lack an intervening capillary network. The arteries and veins are connected in a central nidus (Latin nidus, nest). The lack of capillaries results in direct arteriovenous shunting from the high-pressure arterial system to the low-pressure venous system, which is not designed to accommodate radical fluctuations in pulse pressure. A dural arteriovenous fistula is similar to an arteriovenous malformation but is a direct, high-flow fistula between the external carotid circulation and a dural venous sinus or cerebral cortical vein. An aneurysm is a weakened, focal protrusion of the arterial wall that is often found at a branching point of the cerebral blood vessels. These three types of vascular malformations confer appreciable risks of recurrent $\mathrm{ICH}$, can be identified in the acute stages of $\mathrm{ICH}$ with brain imaging, and are often amenable to treatment intended to prevent rebleeding.

The traditional reference standard for diagnosing arteriovenous malformations, dural arteriovenous fistulae, and aneurysms is catheter intra-arterial digital subtraction angiography (IADSA). This involves inserting a catheter into the femoral artery and guiding it back through the arterial circulation to the common, internal, or external carotid arteries or into the vertebral arteries. Precontrast $\mathrm{x}$-ray images (the 'mask') are taken and then contrast dye is injected from the catheter into the cerebral artery in which it is positioned. Further images are taken during injection and the mask is then subtracted from the post-contrast images. All that remains should be the blood vessels that were filled with contrast material. Images are taken in quick succession during the injection so that radiologists can evaluate blood flow through the arterial system into the venous system. Arteriovenous malformations are typically visualised on IADSA as tangles of abnormal vessels with enlarged feeding arteries and dilated, tortuous veins within the brain substance. Early venous filling during the arterial phase of contrast injection is characteristic of arteriovenous malformations. Dural arteriovenous fistulae appear as early venous filling during the arterial phase of contrast injection via direct connections between dural arteries and a venous sinus or cortical veins within the dura mater covering of the brain. Aneurysms are visualised on IADSA as contrast-filled outpouchings that arise from an arterial wall or bifurcation, although thrombosed aneurysms may be more difficult to appreciate if there is limited contrast penetration.

Given the disparity in the prevalence of moya-moya disease between Asian and non-Asian populations (Scott 2009), we decided to exclude this condition as ethnicities are likely to vary within and between studies.

\section{Index test(s)}

Although IADSA has been used to diagnose these target conditions in the past, CT- and MRI-based techniques are becoming increasingly popular in clinical practice. CT scanners use $\mathrm{x}$-rays to create a series of cross-sectional images of the brain. CT is very useful for identifying acute haemorrhage but cannot reliably detect vascular malformations due to its inability to discriminate blood vessels clearly from the surrounding brain substance. MRI uses the electromagnetic properties of protons to produce highquality cross-sectional images of the brain. Blood vessels are better appreciated on MRI as characteristic 'flow voids'.

More advanced CT and MRI techniques have recently been developed to image blood vessels separately from the brain. CT angiography (CTA) and MR angiography (MRA) exploit CT and MRI techniques to create high-resolution images of the arteries of the brain that can be used to diagnose arteriovenous malformations, dural arteriovenous fistulae, and aneurysms. Both tests combine sophisticated imaging techniques, sometimes involving a precisely timed contrast infusion, to accentuate blood vessels during either 
the arterial or venous phase of contrast perfusion. Hundreds to thousands of images are obtained and reconstructed in a variety of planes so that blood vessels can be visualised in two and three dimensions.

Neither CTA nor MRA is known to be superior to the other. Currently the choice of test ultimately depends on its availability and the patient's ability to undergo the test; for example, patients may have contraindications to MRA or they may be unable to lie still for IADSA under local anaesthetic. The timing of these tests in relation to the $\mathrm{ICH}$ onset may influence diagnostic test accuracy, because the mass effect of ICH may obscure the underlying intracranial vascular malformation. Repeat IADSA, three or more weeks following ICH onset, can detect arteriovenous malformations that were missed on an initial IADSA performed during the acute stages of the bleed (Hino 1998).

\section{Rationale}

In patients who present to hospital with $\mathrm{ICH}$, the swift and accurate identification of any underlying intracranial vascular malformation that may be the underlying cause is important. For instance, patients with ICH caused by arteriovenous malformations seem to fare better than their counterparts with 'primary' ICH, even after adjusting for known prognostic factors (Van Beijnum 2009). Early and accurate diagnosis could improve outcome if treatment prevents recurrent haemorrhage.

Catheter IADSA is the conventional reference standard technique for the diagnosis of arteriovenous malformations, dural arteriovenous fistulae, and aneurysms. However, IADSA is not available in all centres and, because a catheter is required for the procedure, it carries a small but significant risk of stroke, infection, haematoma formation at the catheter entry site, and pseudo-aneurysm formation at the femoral artery puncture site. As a result of their widening availability, lower procedural risks, increasing resolution, and sophisticated reconstruction software, CTA and MRA are often used prior to, or instead of, IADSA in patients with a suspected intracranial vascular malformation following different types of intracranial haemorrhage.

Systematic reviews and meta-analyses have already been performed to determine how the diagnostic accuracy of CTA and MRA compares with IADSA for the detection of aneurysms following subarachnoid haemorrhage (bleeding between the arachnoid and pial meningeal layers that surround the brain) (White 2000; Chappell 2003; Van Gelder 2003; Westerlaan 2011). When we registered our title and protocol for this Cochrane systematic review, there were no meta-analyses of the diagnostic test accuracy of CTA and MRA versus IADSA following ICH. However, two systematic reviews have recently emerged (Ma 2012; Wong 2012), although they did not restrict data to the same reference standard (IADSA). Each review used different inclusion criteria and neither analysed MRA. The quality of included studies were not systematically assessed using validated measures such as the Quality Assessment of Diagnostic Accuracy Studies (QUADAS) tool, heterogeneity among included studies was not analysed in one review (Wong 2012), and the target conditions differed from those evaluated in our analysis. Therefore, we systematically reviewed the literature for studies of the diagnostic accuracy of CTA or MRA compared with IADSA as a reference standard for the detection of intracranial vascular malformations underlying $\mathrm{ICH}$.

\section{O B J E C T I V E S}

To evaluate the diagnostic test accuracy of CTA and MRA versus IADSA for the detection of intracranial vascular malformations as a cause of ICH.

\section{Secondary objectives}

To investigate the influence of the timing of the index and reference tests on diagnostic test accuracy.

\section{Investigation of sources of heterogeneity}

We planned to investigate the differences in diagnostic accuracy in subgroups defined by:

- age;

- ICH volume;

- timing of the index test(s) after symptom onset;

- CT technology (for example non-helical CT scanners, helical CT scanners, and multi-detector helical CT scanners) and MRI technology (for example MRI magnet strength and the type of angiographic technique used to image the arteries);

- the coverage of the brain that is investigated by CTA/MRA in each study (e.g. some users may only evaluate the region around the haematoma while others may choose to also evaluate vessels distant from the bleed);

- the number of arterial territories and orientations investigated by IADSA (e.g. the internal carotid artery territory, the external carotid artery territory, the vertebral artery territory, or all three);

- whether three-dimensional angiography was used;

- differences in the qualifications and experience of the radiologists reporting the index tests and reference standards.

\section{METHODS}

\section{Criteria for considering studies for this review}




\section{Types of studies}

Single or comparative test accuracy studies of CTA or MRA, or both (index tests) versus IADSA (reference standard) in patients with radiographically verified ICH were eligible for inclusion as long as participants underwent at least one index test as well as the reference standard. We included retrospective and prospective case series and cohort studies of consecutive patients (Gluud 2005), irrespective of their date of publication, country, or language of origin. There were no restrictions based on the medical setting in which the tests were performed. We set a minimum overall sample size per study of 20 or more participants. We accepted studies that had fewer than 20 individuals undergoing IADSA as long as the overall study size was greater than 20 participants.

\section{Participants}

We included all participants with ICH (as defined by study authors), who were investigated with one or more index tests and a reference standard. Participants were included irrespective of the severity of their disease as long as they were stable enough to undergo an index test and a reference standard.

\section{Index tests}

We assessed the following index tests.

1. Computed tomography angiography (CTA).

2. Magnetic resonance angiography (contrast enhanced or non-enhanced) (MRA).

\section{Comparator tests}

We sought single test accuracy studies that evaluated CTA or MRA against the IADSA reference standard, as well as comparative studies of CTA versus MRA against the IADSA reference standard.

\section{Target conditions}

The target conditions were aneurysms, arteriovenous malformations, or pial/dural arteriovenous fistulae that have caused $\mathrm{ICH}$. We re-classified patients with moya-moya as 'non-diseased' for the purposes of the review.

\section{Reference standards}

A single reference standard for the diagnosis of intracranial vascular malformations does not exist. In clinical practice, however, expert assessment of IADSA is considered the most valid test and therefore we only included studies that used this test as the reference standard in the review. If studies had used more than one reference standard, we only included these studies if they provided data on patients who had been investigated with IADSA.

\section{Search methods for identification of studies}

\section{Electronic searches}

We searched the following electronic bibliographic databases.

- MEDLINE (Ovid) (1948 to August 2013) (Appendix 1).

- EMBASE (Ovid) (1980 to August 2013) (Appendix 2).

- Database of Abstracts of Reviews of Effects (DARE) ( www.crd.york.ac.uk/crdweb/) (August 2013).

- Health Technology Assessment Database (HTA) ( www.crd.york.ac.uk/crdweb/) (August 2013).

- MEDION (www.mediondatabase.nl/) (August 2013) using the 'Systematic Reviews and Diagnostic Studies' search filter, the ICPC code = 'Neurological' and the signssymp = 'Medical Imaging'.

- ClinicalTrials.gov (August 2013).

- WHO ICTRP (International Clinical Trials Register Portfolio) (August 2013).

We developed comprehensive search strategies for MEDLINE and EMBASE with the help of the Cochrane Stroke Group Information Specialist and adapted these for the other databases. We searched for all relevant studies and did not restrict our searches by date, institution, or language.

\section{Searching other resources}

We searched the reference lists and performed a cited reference search for forward tracking of relevant articles on Google Scholar (http://scholar.google.com/) (August 2013) for all articles that we reviewed for eligibility during the full-text review phase.

\section{Data collection and analysis}

\section{Selection of studies}

One author (CBJ) reviewed titles and abstracts of the records identified from the electronic searches and excluded obviously irrelevant citations. We then obtained the full copy of the remaining papers and the same author together with a second review author (PMW or RA-SS) assessed these to identify relevant studies that met the inclusion criteria for the review. If there was any uncertainty about a study's eligibility we reached a decision through discussion. If there was still uncertainty, we contacted the study authors to ask them to provide the relevant information necessary to resolve the uncertainty. We were not blinded to study authors, institution, and study results during the selection process. 


\section{Data extraction and management}

Two of three review authors (CBJ and PMW or RA-SS) independently extracted data using a standardised data collection form. We accepted the authors' definitions of a positive index/comparator/reference test result for arteriovenous malformations, dural arteriovenous fistulae, and aneurysms.

The absolute numbers of observations of true positives, false positives, true negatives, and false negatives had to be specified or had to be able to be derived from the available data in order to be formally meta-analysed. We contacted study authors if this was not possible; if these data could not be obtained, despite contacting the authors, then we excluded the study. We excluded studies if they were a reanalysis or republication of data from a study population that was already included in the review.

We compared the data abstracted by two review authors (CBJ and PMW or RA-SS) and resolved any disagreements through discussion. We used the extracted raw data to construct $2 \times 2$ contingency tables for outcomes defined as any of the target conditions detected. We used the 2 x 2 contingency tables to calculate sensitivity and specificity for each index test in all included studies using RevMan 5.2 (RevMan 2012).

We extracted the following additional study-level attributes.

1. General information: title, journal (including volume and pages), year, institution and country, language, and study design.

2. Population sampling: number of participants screened, number eligible, number enrolled, and number undergoing both the index tests (CTA or MRA, or both) and the reference standard (IADSA).

3. Demographic characteristics: participant age, ethnicity, number with pre-existing hypertension, number with a prior intracranial haemorrhage.

4. Radiological description of the ICH: volume, location, and extension of the intracerebral haemorrhage.

5. Index test parameters for: (1) CTA: manufacturer and model, equipment (non-helical CT, helical CT, or multi-detector CT), slice thickness, pitch, matrix, field of view, coverage, contrast agent, delay to contrast infusion, contrast volume and rate of infusion, reformatting technique and image format; and (2) MRA: manufacturer and model, magnet strength, sequences, contrast agent and rate of infusion, slice thickness, matrix, field of view, and coverage. We also recorded the number of indeterminate scans and the number and types of adverse events.

6. Reference standard parameters for IADSA: manufacturer and model, the arterial territories imaged (unilateral or bilateral internal carotids, unilateral or bilateral external carotids, and unilateral or bilateral vertebral arteries), number of projections (views) per artery, use of three-dimensional angiography, frame rate, and matrix. We recorded the number of indeterminate results and the number and types of adverse events.

We contacted the authors of studies that might have been subject to differential verification bias because they had used more than one reference standard. We requested the raw data in order to recalculate the $2 \times 2$ contingency tables according to our definition of the target condition. We constructed the new contingency tables using only IADSA as the reference standard. We therefore excluded participants who underwent a reference standard other than IADSA from the analysis.

There was likely to be inter-study variation in the positivity threshold due to the fact that scans must be interpreted based on judgement rather than on an explicit quantitative cut-point (Macaskill 2010). We therefore planned to organise the data according to different thresholds if there were obvious discrepancies in the definition of a positive test result. We planned to exclude uninterpretable scans from the contingency tables and evaluate them in a sensitivity analysis if we encountered this issue.

\section{Assessment of methodological quality}

We assessed the methodological quality of each study using a modified version of the QUADAS tool (Whiting 2003). QUADAS appraises study quality by indicating the presence or absence of 14 key criteria through a series of questions that are answered as 'yes', 'no', or 'unclear'. The Cochrane Handbook for Systematic Reviews of Diagnostic Test Accuracy advises omitting three items that relate mainly to the quality of reporting rather than the quality of the methodology.

In addition to the Cochrane recommended QUADAS questions, we have added an extra criterion to evaluate whether those interpreting the index test were of an appropriate level of training that we have defined as either an 'expert' radiologist (a neuroradiologist) or an 'experienced' radiologist (consultant level or equivalent radiologist with five or more years of clinical practice).

This modified 12-item quality assessment form is available as Appendix 3.

Two review authors (CBJ and RA-SS) independently assessed study quality and a third review author (PMW) checked the index test and reference standard attributes. Disagreements were mediated through arbitration.

\section{Statistical analysis and data synthesis}

We calculated sensitivity and specificity, with $95 \%$ confidence intervals (CI), for each index test in all studies. We used RevMan 5.2 to create coupled forest plots to visually evaluate the variation in the estimates of sensitivity and specificity between studies (RevMan 2012). We plotted the results in receiver operator characteristic (ROC) space. Sensitivity was used to define the yaxis, specificity defined the $\mathrm{x}$-axis, and each point on the plot represents the proportion of true positives amongst those with our defined target conditions against the proportion of false positives amongst those lacking our defined target conditions for one particular study.

We planned to conduct a meta-analyses of study-specific pairs of sensitivity and specificity to calculate pooled estimates of sensitivity and specificity using the bivariate method (Macaskill 2010). 
We performed the analyses using RevMan 5.2 (RevMan 2012) and obtained pooled estimates using the Metandi package within the Stata Statistical Software version 12.1 (StataCorp 2011).

\section{Investigations of heterogeneity}

We planned to address heterogeneity by adding covariates of interest to the bivariate model. As described in the introduction, covariates included equipment parameters for CTA, MRA, and IADSA, the experience of those reading the index test and reference standard, the timing of the index test with respect to symptom onset, the average participant age, and the average haematoma size.

\section{Sensitivity analyses}

We planned sensitivity analyses to evaluate the robustness of our eligibility criteria by exploring the effect of including only adults (as opposed to all age groups) on the pooled sensitivity and specificity results. We also planned to undertake sensitivity analyses for each of the 12 modified QUADAS criteria described in Appendix 3 to determine the effect of poor study quality on the overall results. If feasible, we intended to perform a sensitivity analysis on the effect of excluding uninterpretable index test results by instead re-classifying them as a negative result. We planned to perform these analyses when more than three studies were available for each strata.

\section{Assessment of reporting bias}

We contacted the authors of the studies that were excluded because they did not report specific outcome measures of interest to inquire whether these data were available but had not been published. If data were available and met the inclusion criteria, we included them in our analysis.

We planned to assess publication bias using the method described by Deeks 2005 if there were a sufficient number of studies available.

\section{RE S U L T S}

\section{Results of the search}

The MEDLINE and EMBASE searches identified 4472 unique citations. Of these, we considered 37 relevant to the purpose of our review. We retrieved full-text articles and subsequently excluded 26 following review. We were unsure about whether two articles could be included but ultimately excluded them since the corresponding author did not reply to our requests for additional information (Sasiadek 2000; Sasiadek 2002). We excluded the remaining articles because the index test was not computed tomography angiography (CTA)/magnetic resonance angiography (MRA) ( $\mathrm{n}=2$ ) (Pott 1992; Kadkhodayan 2012), intra-arterial digital subtraction angiography (IADSA) was not the reference standard ( $n=8$ ) (Awad 1992; Hünerbein 2003; Lee 2007; Elhammady 2008; Sha 2008; Bekelis 2012; Wijman 2012; Kamel 2013), there was no comparison between CTA/MRA and IADSA ( $n=1$ ) (Zheng 2012), the article was a review rather than original research $(\mathrm{n}=6)$ (Bowen 2007; Truwit 2007; Kidwell 2010; Campeau 2012; Chandra 2012; Khosravani 2013), the overall study size was smaller than 20 participants $(\mathrm{n}=1)($ Evans 2005), or the study was not performed on patients presenting with $\mathrm{ICH}$ $(\mathrm{n}=6)$ (Fasulakis 2003; Dammert 2004; Griffiths 2006; Gross 2012; Leung 2012; Li 2013).

Eleven studies, each published as an individual report, comprising a total of 927 participants, met our inclusion criteria (Figure 1). Eight studies compared CTA with IADSA (Eshwar Chandra 1998; Murai 1999; Delgado Almandoz 2009; Romero 2009; Yeung 2009; Yoon 2009; Wong 2011; Ma 2012) and three studies compared MRA with IADSA (Wong 2010; Lummel 2012; Zhou 2012). The details of included studies are described in the Characteristics of included studies table. 
Figure I. Study flow diagram.

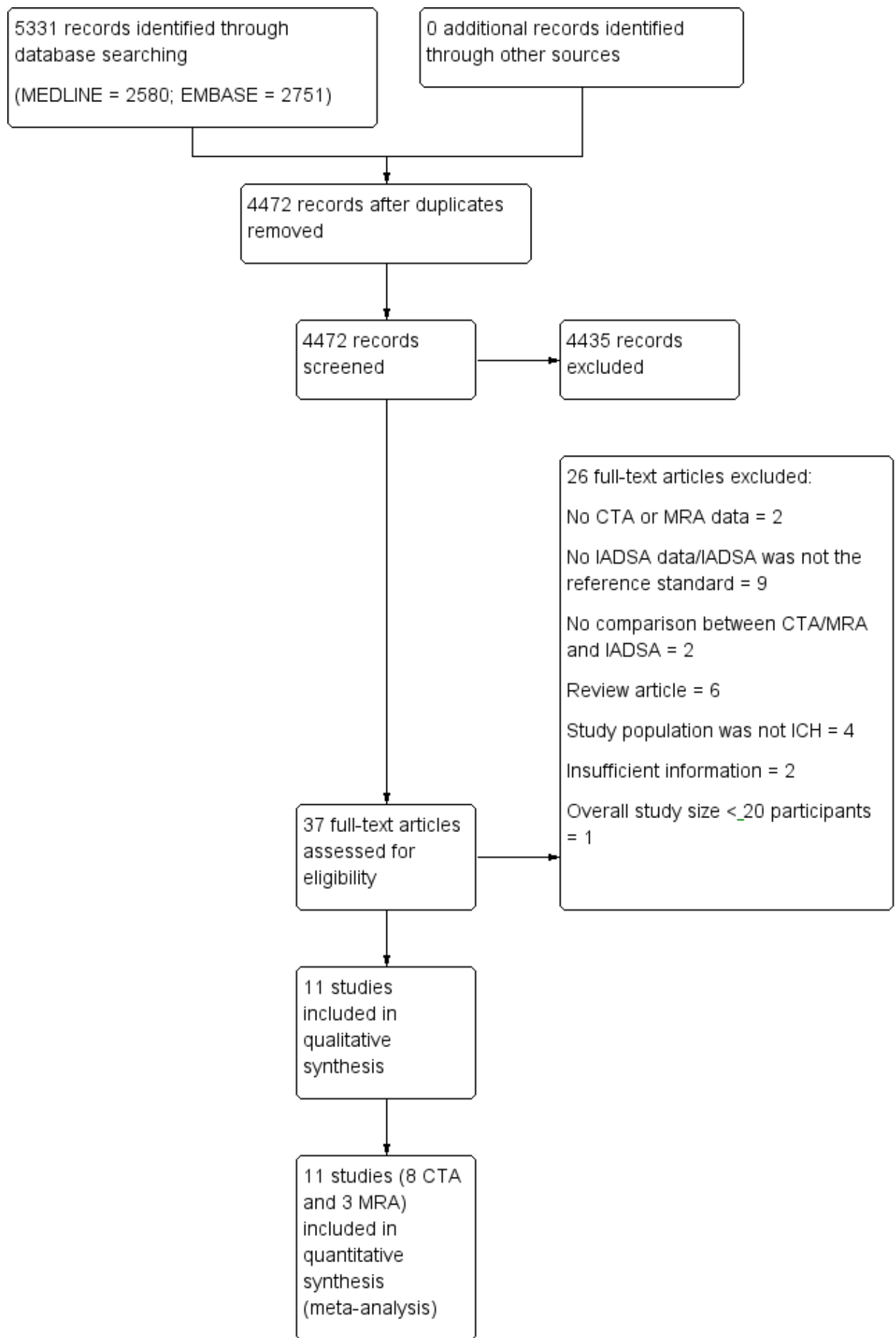




\section{Methodological quality of included studies}

The quality of the 11 included studies varied considerably when evaluated according to our modified QUADAS criteria (Figure 2). Five were prospective (all CTA studies, 354 participants), five were retrospective (three CTA studies, 172 participants; two MRA studies, 218 participants), and the design of one study was unclear (MRA, 183 participants). All studies apart from one failed to provide a formal definition of a positive scan apart from general statements about identification of a vascular or 'secondary' cause for the ICH. 
Figure 2. Methodological quality summary: review authors' judgements about each methodological quality item for each included study.

\begin{tabular}{|c|c|c|c|c|c|c|c|c|c|c|c|c|}
\hline & 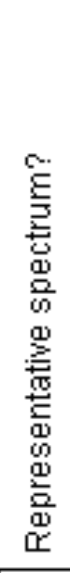 & 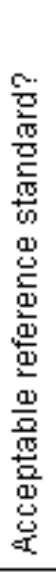 & 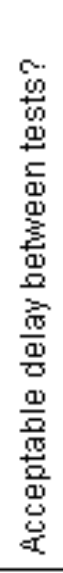 & 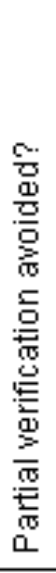 & 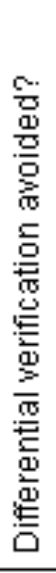 & 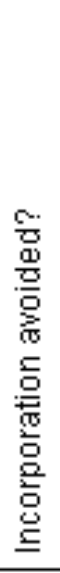 & 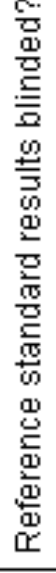 & 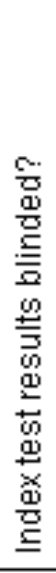 & 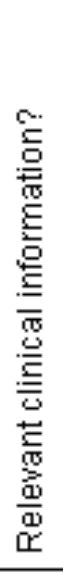 & 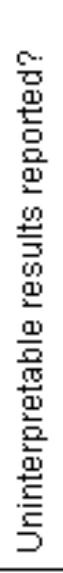 & 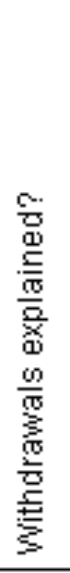 & 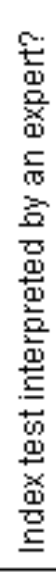 \\
\hline \multirow[t]{2}{*}{ Delgado Almandoz 2009} & & $?$ & 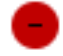 & 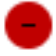 & + & + & $?$ & + & 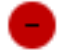 & $?$ & + & + \\
\hline & & $?$ & 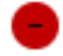 & + & + & + & $?$ & $?$ & $?$ & $?$ & + & $?$ \\
\hline Lummel 2012 & & $?$ & & & + & + & ค & + & & $?$ & + & + \\
\hline Ma 2012 & & $?$ & & + & + & + & + & + & & $?$ & + & + \\
\hline Murai 1999 & & $?$ & & & + & + & $?$ & $?$ & $?$ & $?$ & + & + \\
\hline Romero 2009 & & $\oplus$ & + & & + & + & ค & + & & $?$ & + & \\
\hline Wong 2010 & & $\oplus$ & + & & $\oplus$ & + & $\oplus$ & + & $?$ & $?$ & + & + \\
\hline Wong 2011 & & $\odot$ & + & $\oplus$ & $\oplus$ & + & 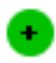 & 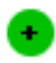 & - & $?$ & + & + \\
\hline Yeung 2009 & + & + & + & & + & + & $?$ & + & 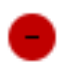 & $?$ & + & + \\
\hline Yoon 2009 & + & + & + & + & + & + & + & + & $?$ & $?$ & + & + \\
\hline Zhou 2012 & + & $\oplus$ & & & $\oplus$ & + & $?$ & $?$ & $?$ & $?$ & + & \\
\hline
\end{tabular}

Computed tomography angiography or magnetic resonance angiography for detection of intracranial vascular malformations in patients with intracerebral haemorrhage (Review)

Copyright $\odot 2014$ The Cochrane Collaboration. Published by John Wiley \& Sons, Ltd. 


\section{Representative spectrum}

\section{CTA}

Eight studies comprising a total of 526 participants compared CTA with IADSA. All studies described their inclusion criteria. However, only two studies comprising a total of 133 participants (Figure 2) met our definition of a representative spectrum (Appendix 3).

Sample size for all eight studies ranged from 31 to 210 . The mean or median age of participants in each study ranged from 28 to 56 years. Two studies included participants under 16 years of age (Eshwar Chandra 1998; Romero 2009). Two studies did not document mean or median participant age (Delgado Almandoz 2009; Ma 2012). The proportion of females ranged from $33 \%$ to $54 \%$. Two studies did not document gender distribution (Delgado Almandoz 2009; Ma 2012). One study reported the proportion of participants with pre-existing hypertension at the time of $\mathrm{ICH}$ (14\%) (Romero 2009). No study indicated how many participants had experienced prior ICH.

Three studies documented the types of intracranial haemorrhage at the time of presentation (Romero 2009; Yoon 2009; Wong 2011). The proportion presenting with 'pure' ICH ranged from $10 \%$ to $56 \%$. The proportion presenting with ICH and subarachnoid haemorrhage (SAH) ranged from $9 \%$ to $39 \%$, the proportion presenting with $\mathrm{ICH}$ and intraventricular haemorrhage (IVH) ranged from $10 \%$ to $34 \%$, and the proportion presenting with $\mathrm{ICH}$ and a subdural haematoma (SDH) ranged from 3\% to $17 \%$. Two studies (Romero 2009; Yoon 2009) contained participants who presented with ICH combined with both SAH and IVH (23\% and $8 \%$ of participants respectively). One study contained participants with ICH and simultaneous SAH, IVH, and SDH (5\%) (Romero 2009). Five studies reported the location of the presenting ICH (Eshwar Chandra 1998; Romero 2009; Yeung 2009; Yoon 2009; Wong 2011). The presenting ICH was lobar in $56 \%$ to $100 \%$ of cases, deep in $0 \%$ to $19 \%$ of cases, and infratentorial in $0 \%$ to $21 \%$ of cases. No study reported the mean or median ICH volume at presentation.

\section{MRA}

Three studies comprising a total of 401 participants compared MRA with IADSA. The inclusion and exclusion criteria were clearly described and the patient population met our definition of a representative spectrum in two of three studies (Appendix 3). The mean age ranged from 42 years (standard deviation (SD) 15) to 53.4 years (range 14 to 82 ). The proportion of females ranged from $34 \%$ to $54 \%$. Participant withdrawals were explained but there was no documentation about whether adverse events were encountered. All participants could be accounted for in the studies. The proportion with pre-existing hypertension was $28 \%$ and $34 \%$ in the two studies that reported these data (Wong 2010; Zhou 2012). It is unclear whether any of the participants had experienced prior ICH.

One study documented the types of intracranial haemorrhage at the time of presentation (Wong 2010). Nineteen patients presented with ICH and concomitant IVH. The presenting ICH was lobar in $53 \%$ of cases, deep in $32 \%$ of cases, and infratentorial in $15 \%$ of cases. The mean or median ICH size at the time of presentation was not reported.

\section{Acceptable reference standard}

\section{CTA}

We deemed the reference standard to be of unclear quality in four studies (Eshwar Chandra 1998; Murai 1999; Delgado Almandoz 2009; Ma 2012), which did not document the equipment, technical specifications, and the level of expertise of those interpreting the IADSA in sufficient detail. A neuroradiologist interpreted the IADSA in five studies (Romero 2009; Yeung 2009; Yoon 2009; Wong 2010; Ma 2012); the expertise of those interpreting the IADSA was not documented in three studies (Eshwar Chandra 1998; Murai 1999; Delgado Almandoz 2009), and one study used a combination of an expert neuroradiologist and a neurosurgeon (Wong 2011).

\section{MRA}

We deemed the reference standard to be of unclear quality in one study (Lummel 2012), which did not document the equipment, technical specifications, and the level of expertise of those interpreting the IADSA in sufficient detail. A neuroradiologist interpreted the IADSA in two studies (Wong 2010; Lummel 2012), while the level of expertise of those interpreting the IADSA was not documented in the third study (Zhou 2012).

\section{Acceptable delay between tests}

\section{CTA}

Three studies documented time from ICH symptom onset to the CTA (one study had a mean of six hours from symptom onset to CTA (Murai 1999), one studied required that the CTA be performed $\leq 24$ hours from ICH onset (Delgado Almandoz 2009), one study required the CTA to be performed $\leq 120$ hours from

Computed tomography angiography or magnetic resonance angiography for detection of intracranial vascular malformations in patients 
ICH onset (Wong 2011)), and one study documented the time from ICH symptom onset to IADSA (IADSA had to be completed $\leq 144$ hours from ICH onset (Wong 2011)). Three studies reported on the mean or median interval from CTA to IADSA. All IADSA examinations were performed within 48 hours of the CTA in one study (Romero 2009), IADSA was performed a median of two days from the CTA in one study (Yeung 2009), and there was a mean of 16.1 hours (SD 9 hours) between the CTA and IADSA in the third study (Yoon 2009).

\section{MRA}

The time from ICH symptom onset to both the index test and reference standard ranged from six to 18 weeks in the one MRA study that reported these values (Wong 2010).

\section{Partial verification bias avoided}

\section{CTA}

Three studies avoided partial verification bias by prospectively recruiting patients with the intention that each participant would undergo both CTA and IADSA (Yoon 2009; Wong 2011; Ma 2012). It was unclear whether the results of the CTA influenced the selection of those undergoing IADSA in one study (Eshwar Chandra 1998). The CTA result influenced the timing of IADSA in one prospective study (Murai 1999), and certainly would have influenced the decision to perform IADSA in the three retrospective studies (Delgado Almandoz 2009; Romero 2009; Yeung 2009).

\section{MRA}

Partial verification bias would be expected to be present in all three retrospective studies (Wong 2010; Lummel 2012; Zhou 2012), since the results of the MRA would certainly influence the decision to proceed to IADSA in routine clinical practice.

\section{Differential verification bias}

\section{CTA}

Three studies used a combination of IADSA and pathology or operative findings as a reference standard (Eshwar Chandra 1998; Delgado Almandoz 2009; Romero 2009). We contacted study authors and extracted data related only to those participants undergoing both CTA and IADSA. This may have introduced a form of selection bias as those undergoing pathological confirmation may have had larger ICH volumes (leading to surgery or death) that could have obscured the target condition on imaging. However, it does remove the influence of differential verification bias. All other studies used IADSA as the exclusive reference standard.

\section{MRA}

All studies restricted the reference standard to IADSA.

\section{Incorporation bias}

Incorporation bias was avoided in all 11 included studies.

\section{Reference standard result blinded}

\section{CTA}

Three of five prospective studies explicitly mention that IADSA was interpreted blinded to the index result (Yoon 2009; Wong 2011; Ma 2012). Two neuroradiologists in one retrospective study read the IADSA at least one month after the CTA (Yeung 2009). However, while this would reduce the risk of recall bias, it would not eliminate it altogether. One retrospective study reported that the IADSA scans were reported with knowledge of the CTA results (Romero 2009).

\section{MRA}

One retrospective study explicitly mentioned that IADSA was interpreted blinded to the index result (Wong 2010). The blinding status was unclear in one study (Zhou 2012) and the final study involved interpretation of the IADSA with knowledge of the results of the MRA (Lummel 2012).

\section{Index test result blinded}

\section{CTA}

The index test was interpreted blinded to the results of the IADSA in six studies (Delgado Almandoz 2009; Romero 2009; Yeung 2009; Yoon 2009; Wong 2011; Ma 2012), while no statement to this effect was made in the remaining two studies (Eshwar Chandra 1998; Murai 1999).

\section{MRA}

The index test was interpreted blinded to the results of the IADSA in two studies (Wong 2010; Lummel 2012), while no statement to this effect was made in the remaining study (Zhou 2012). 


\section{Relevant clinical information}

\section{CTA}

Five studies required that the CTA and IADSA were interpreted blinded to the participant's clinical information (Delgado Almandoz 2009; Romero 2009; Yeung 2009; Wong 2011; Ma 2012), while the three remaining studies did not address this point (Eshwar Chandra 1998; Murai 1999; Yoon 2009).

\section{MRA}

Two studies required that the MRA and IADSA were interpreted blinded to the participant's clinical information (Wong 2010; Lummel 2012), while the one remaining study did not address this point (Zhou 2012).

\section{Uninterpretable results reported}

No study documented whether uninterpretable images were encountered.

\section{Withdrawals explained}

No study reported whether there were participants who had to withdraw due to adverse events or due to an inability to tolerate the index test or reference standard. All participants could be accounted for in each study but the process by which the final study population was reached was unclear in three studies (Eshwar Chandra 1998; Yeung 2009; Wong 2011).

\section{Index tests interpreted by an expert}

\section{CTA}

A neuroradiologist interpreted the CTA in six studies. CTA was interpreted by either a neuroradiologist or neurosurgeon in one study (Murai 1999) and the level of expertise of those interpreting the dynaCT scan was not clear in one study (Eshwar Chandra 1998).

\section{MRA}

MRA images were interpreted by neuroradiologists or neurosurgeons in two studies (Wong 2010; Zhou 2012) and were interpreted exclusively by neuroradiologists in the final study (Lummel 2012).

\section{Findings}

\section{Studies on CTA}

Figure 3 shows the paired forest plot for sensitivity and specificity for CTA compared with IADSA. The pooled estimates of sensitivity and specificity were 0.95 (95\% CI 0.90 to 0.97$)$ and $0.99(95 \%$ CI 0.95 to 1.00 ) respectively (Figure 4). Approximately $85 \%$ of the estimates of specificity were close to or at the 'ceiling level' (specificity of 1.00). The pooled positive likelihood ratio was 73 ( $95 \%$ CI 19 to 277 ) and the negative likelihood ratio was 0.06 (95\% CI 0.03 to 0.10 ). 
Figure 3. Forest plot of the paired sensitivity and specificity values for the detection of an intracranial vascular malformation following intracerebral haemorrhage using computed tomography angiography (CTA) or magnetic resonance angiography (MRA) compared to a reference standard of catheter intra-arterial digital subtraction angiography.

CTA

Study
Delgado Almandoz 2009
Eshwar Chandra 1998
Ma 2012
Murai 1999
Romero 2009
Wong 2011
Yeung 2009
Yoon 2009

$\begin{array}{rrrrr}\text { TP } & \text { FP } & \text { FN } & \text { TN } & \text { Sensitivity }(95 \% \text { Cl) } \\ 41 & 1 & 3 & 63 & 0.93[0.81,0.99] \\ 21 & 1 & 3 & 19 & 0.88[0.68,0.97] \\ 29 & 0 & 2 & 61 & 0.94[0.79,0.99] \\ 5 & 0 & 1 & 25 & 0.83[0.36,1.00] \\ 13 & 0 & 0 & 4 & 1.00[0.75,1.00] \\ 24 & 1 & 0 & 84 & 1.00[0.86,1.00] \\ 20 & 3 & 0 & 24 & 1.00[0.83,1.00] \\ 17 & 0 & 1 & 60 & 0.94[0.73,1.00]\end{array}$

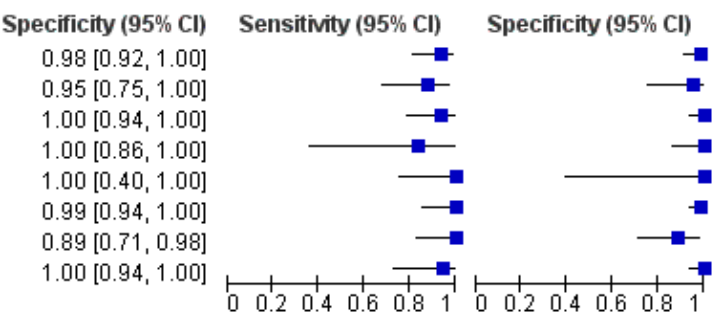

MRA

Study

TP FP FN TN Sensitivity $(95 \% \mathrm{Cl})$ Specificity $(95 \% \mathrm{Cl})$

Lummel 2012

$\begin{array}{rrrr}6 & 1 & 0 & 60 \\ 50 & 1 & 0 & 100\end{array}$

$1.00[0.54,1.00]$

$0.98[0.91,1.00]$

Wong 2010

$\begin{array}{llll}50 & 1 & 0 & 100 \\ 62 & 1 & 4 & 116\end{array}$

$1.00[0.93,1.00]$

$0.99[0.95,1.00]$

Zhou 2012

$0.94[0.85,0.98]$

$0.99[0.95,1.00]$

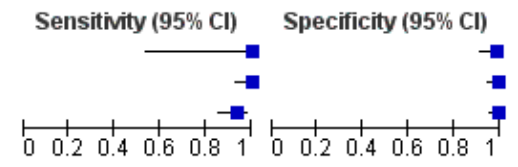


Figure 4. Pooled estimates of sensitivity and specificity for computed tomography angiography (black) and magnetic resonance angiography (red) plotted in receiver operator characteristic space of studies compared with catheter intra-arterial digital subtraction angiography for the detection of intracranial vascular malformations following intracerebral haemorrhage.

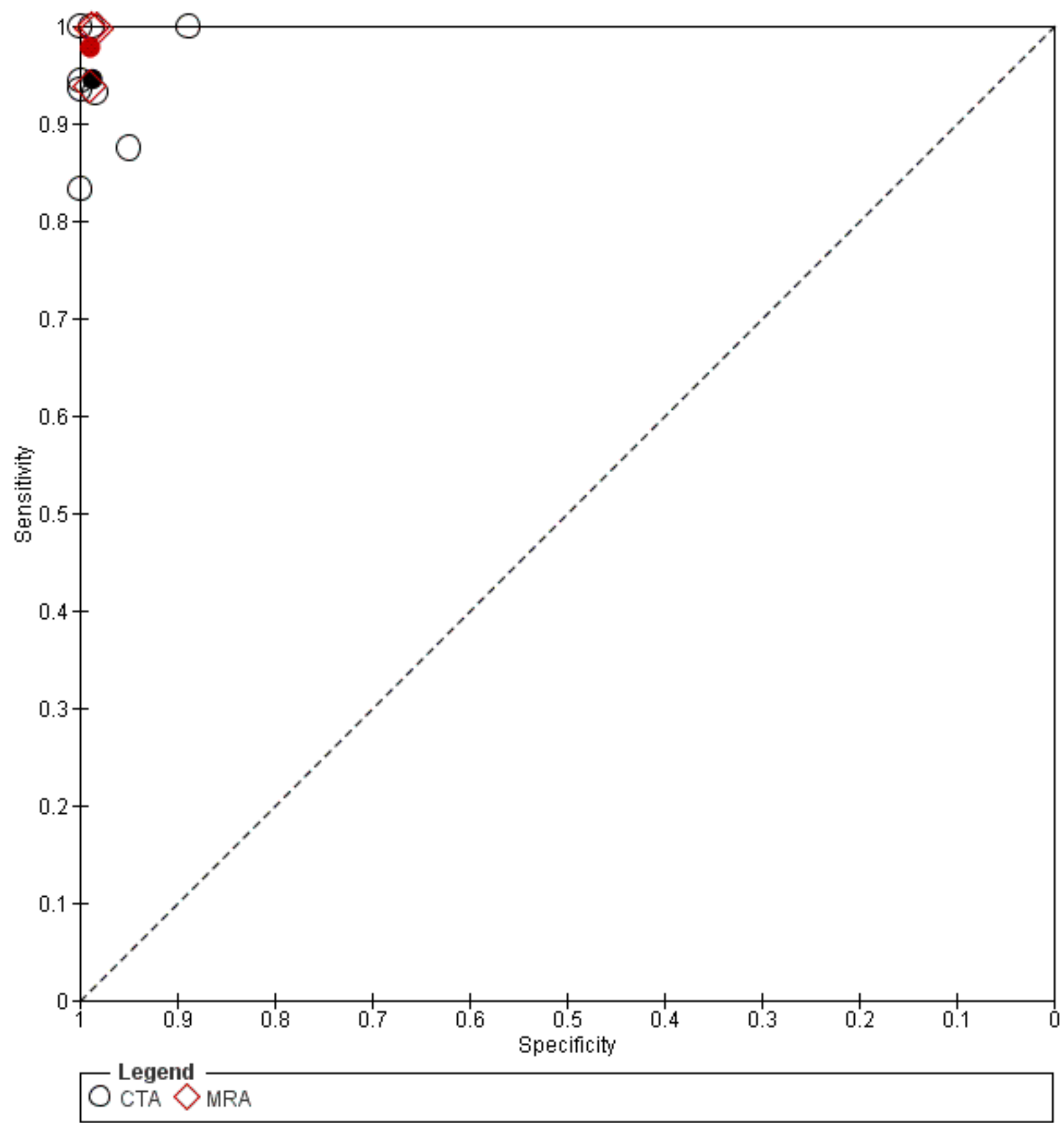

Computed tomography angiography or magnetic resonance angiography for detection of intracranial vascular malformations in patients with intracerebral haemorrhage (Review)

Copyright $\odot 2014$ The Cochrane Collaboration. Published by John Wiley \& Sons, Ltd. 
The results remained robust in a sensitivity analysis in which six studies that recruited only adult patients, comprising 465 participants, were evaluated separately (Murai 1999; Delgado Almandoz 2009; Yeung 2009; Yoon 2009; Wong 2011; Ma 2012). The pooled estimates of sensitivity and specificity were 0.95 (95\% CI 0.89 to 0.98 ) and 0.99 (95\% CI 0.95 to 1.00 ).

We performed sensitivity analyses when more than three studies for each analysis were available. The results remained robust in the following pre-specified sensitivity analyses where only those meeting each study criterion were analysed.

- Acceptable reference standard (four studies, 251

participants): sensitivity 0.99 (95\% CI 0.79 to 1.00$)$ and specificity 0.98 (95\% CI 0.88 to 1.00$)$.

- Delay between tests reported (four studies, 251 participants): sensitivity 0.99 (95\% CI 0.79 to 1.00$)$ and specificity 0.98 (95\% CI 0.88 to 1.00$)$.

- Partial verification bias avoided (four studies, 323 participants): sensitivity 0.94 (95\% CI 0.90 to 0.97 ) and specificity 0.99 ( $95 \%$ CI 0.96 to 1.00 ).

- Index test results blinded (six studies, 451 participants): sensitivity 0.96 (95\% CI 0.90 to 0.99$)$ and specificity 0.99 (95\% CI 0.94 to 1.00 ).

- Index test interpreted by an expert (seven studies, 482 participants): sensitivity 0.96 (95\% CI 0.90 to 0.98 ) and specificity 0.99 ( $95 \%$ CI 0.95 to 1.00 ).

We were unable to perform sensitivity analyses for differential verification bias (all studies met the criterion), incorporation bias (all studies met the criterion), relevant clinical information provided to those interpreting the test (no study met this criterion), reporting and reclassifying uninterpretable images as negative (no study met this criterion), and explanation of study withdrawals (all studies met this criterion).

Although there were sufficient data available (more than $85 \%$ complete for all studies) to address heterogeneity between studies according to gender, mean or median age, equipment parameters, and experience of those interpreting the CTA, the shortage of available studies $(\mathrm{n}=8)$ precluded formal analysis of heterogeneity. However, there was no indication of heterogeneity based on visual inspection of the forest and ROC plots and the low variance estimates. There were insufficient data to assess heterogeneity according to the equipment parameters of IADSA, the experience of those interpreting the IADSA studies, the timing of the CTA with respect to symptom onset, and average haematoma size.

No studies reported adverse events.

We did not formally evaluate publication bias due to the limited number of studies (Deeks 2005).

\section{Studies on MRA}

Figure 3 shows the paired forest plot for sensitivity and specificity for MRA compared with IADSA. The pooled estimates of sensitivity were 0.98 (95\% CI 0.80 to 1.00$)$ and for specificity were 0.99 (95\% CI 0.97 to 1.00 ) for the three studies (Figure 4). The corresponding positive likelihood ratio was 91 (95\% CI 22 to $376)$ and the negative likelihood ratio was 0.02 (95\% CI 0.002 to $0.234)$.

We could not perform our pre-specified sensitivity analyses due to the limited number of studies.

No studies reported adverse events.

We did not formally evaluate publication bias due to the limited number of studies (Deeks 2005).

\section{Comparison of CTA and MRA}

Using all included studies, we compared the diagnostic accuracy of CTA and MRA by adding covariate terms for test type to the parameters of the bivariate model to determine the effect of test type on sensitivity and specificity. We used a likelihood ratio test to assess the statistical significance of the difference in sensitivity and specificity between tests by comparing models with and without the covariate terms in the bivariate model. The likelihood ratio test indicated no evidence ( $\mathrm{P}$ value $=0.6$ ) of a difference in sensitivity or specificity, or both between CTA and MRA (Figure 4; Summary of findings). Indirect comparisons can be prone to confounding, however, and direct comparisons between CTA and MRA are currently lacking. 


\section{Summary of findings}

Population

Setting

Index test CTA or MRA

\section{Reference standard $\quad$ Catheter IADSA}

Number of studies $\quad 8$ cross-sectional studies that evaluated CTA and IADSA in the same patient population and 3 cross-sectional studies that evaluated MRA and IADSA in the same patient population

\begin{tabular}{llllll}
\hline Test & Studies & Cases & Total & Summary sensitivity $(\mathbf{9 5 \%}$ Cl) & Summary specificity $(\mathbf{9 5 \%} \mathbf{C l})$ \\
\hline CTA & 8 & 180 & 526 & $0.95(0.90$ to 0.97$)$ & $0.99(0.95$ to 1.00$)$ \\
\hline MRA & 3 & 122 & 401 & $0.98(0.80$ to 1.00$)$ & $0.99(0.97$ to 1.00$)$ \\
\hline
\end{tabular}

Comparison of CTA and MRA In studies of variable methods and degrees of bias, the diagnostic accuracy of both CTA and MRA appear comparable to IADSA for detection of intracranial vascular malformations following intracerebral haemorrhage. There was no evidence to suggest a difference in sensitivity or specificity, or both, between CTA and MRA (P value $=0.6)$. However, there was no study that directly compared the accuracy of CTA and MRA

CAUTION: The results on this table should not be interpreted in isolation from the results of the individual included studies contributing to each summary test accuracy measure. These are reported in the main body of the text of the review

Cl: confidence interval 


\section{ISCUSSION}

This systematic review and meta-analysis identified eight studies comparing the diagnostic accuracy of computed tomography angiography (CTA) with intra-arterial digital subtraction angiography (IADSA) and three studies comparing magnetic resonance angiography (MRA) with IADSA. The pooled estimates of sensitivity and specificity were 0.95 (95\% confidence interval (CI) 0.90 to 0.97 ) and 0.99 (95\% CI 0.95 to 1.00$)$ respectively for CTA and 0.98 (95\% CI 0.89 to 1.00$)$ and 0.99 (95\% CI 0.98 to 1.00) respectively for MRA. Studies were of variable methodological quality with discrepant inclusion criteria, retrospective designs, and high rates of partial verification bias.

\section{Summary of main results}

The Summary of findings summarises our findings for the eight included studies comparing CTA with IADSA and the three studies comparing MRA with IADSA. CTA and MRA appear equivalent to IADSA for the detection of intracranial vascular malformations following intracerebral haemorrhage (ICH). However, it is important to consider that sample sizes were typically small and study designs varied. High rates of partial verification bias (50\%) complicate evaluation of sensitivity. Inflated estimates of sensitivity would be expected in situations where the index test is used to select participants for the reference standard. Furthermore, differential verification bias had complicated studies that used IADSA, pathology, or a combination of pathology and IADSA as a reference standard; we mitigated this effect by restricting our analyses to participants in whom IADSA had been the reference standard. The majority of included studies were 'streamlined' to select a patient population with the greatest likelihood of harbouring an underlying vascular malformation or aneurysm. Focused exclusion of patients with alternative diagnoses can falsely elevate specificity since disease mimics are preferentially excluded. Studies excluding patients with pre-existing hypertension or deep haemorrhages, a population of patients with a lower yield of aneurysms and arteriovenous malformations on IADSA performed following ICH (Cordonnier 2010), would be particularly prone to this phenomenon. In addition, broad selection criteria are required as certain subgroups of patients, such as those older than 50 , have been found to have an appreciable yield of vascular malformations and aneurysms on IADSA following ICH despite a common perception to the contrary (Cordonnier 2010).

The timing of the CTA, MRA, and IADSA, both in respect to each other and from the onset of symptoms, would also be expected to exert a major influence on overall estimates of diagnostic accuracy. The haemorrhage could obscure the vascular malformation or aneurysm if the scan is performed too early. Almost half of the studies did not report time from symptom onset to CTA, only one study recorded the time from symptom onset to IADSA, and less than half reported the delay between CTA and IADSA. Likewise, although all three MRA studies reported time from symptom onset to index test, none of them reported the delay between the MRA and IADSA. The optimal timing of scans has not been established but reporting duration and correlating it with accuracy is a crucial step to resolving this uncertainty.

\section{Strengths and weaknesses of the review}

We used a comprehensive search strategy on eight major electronic databases without any restrictions on date, language, or country of origin. We identified studies both with and without a diagnostic test accuracy filter incorporated into the search strategy.

We minimised patient overlap by only selecting the most recent study published where there were many from the same patient cohort. Two review authors evaluated selected full studies for inclusion and a combination of two of three review authors (CBJ and PMW or RA-SS) with complementary expertise (two neurologists and one neuroradiologist) independently extracted data and assessed study quality.

The main limitations pertain to the dearth of studies and quality of the evidence. We identified few studies, methodological quality was variable, sample sizes were small, and there was incomplete reporting of patient and test characteristics.

These issues are common in studies of diagnostic test accuracy and tend to lead to overestimation of diagnostic performance, especially when performed using a narrow spectrum of patients (Lijmer 1999; Rutjes 2006). Adherence to the Standards for Reporting of Diagnostic Accuracy (STARD) guidelines will facilitate optimal design and reporting of future studies (Bossuyt 2003).

We did not identify any comparative test accuracy studies (i.e. studies that compared CTA with MRA using IADSA as the reference standard). Due to limited studies and minimal heterogeneity we were not able to perform in-depth sensitivity analyses evaluating the contribution of study quality to the overall estimates of sensitivity and specificity. Similarly, we could not evaluate all prespecified features of interest for heterogeneity due to inconsistent reporting. We also could not investigate heterogeneity and publication bias due to insufficient studies and small sample sizes.

We were unable to evaluate practicality and applicability formally due to a lack of information on patient tolerability, the frequency with which uninterpretable scans were encountered, the consequences of false negative diagnoses, and measures of cost-effectiveness.

\section{Applicability of findings to the review question}

Both CTA and MRA appear comparable to IADSA for the detection of intracranial vascular malformations following ICH. However, routine use of CTA and MRA will need to take into account practicality and cost-effectiveness. CTA is quicker and less invasive 
than IADSA. Patient tolerability is therefore improved, making it a more practical option for critically ill patients. It is also more widely available and more easily accessible that IADSA. Likewise, MRA is also less invasive and, though not as appropriate for critically ill patients, its adverse event profile compares favourably to CTA since it does not require radiation. Although less available than CTA, it is at least as accessible as IADSA. IADSA is a more demanding procedure requiring operators with highly specialised training in interventional techniques. However, although CTA and MRA are relatively low-risk procedures, they can cause contrast reactions and the overall risk of adverse events has yet to be formally compared with IADSA. For instance, in certain circumstances, patient radiation exposure may be greater with CTA compared with IADSA (Manninen 2012).

The consequences of a false negative diagnosis have yet to be evaluated. A missed intracranial vascular malformation may predispose the patient to recurrent ICH or may simply necessitate IADSA, which potentially negates the value of CTA or MRA as first-line imaging modalities. Neuroradiologists in the included studies were routinely denied access to basic clinical information, creating an artificial situation that is not representative of routine clinical practice. A practical benefit to IADSA is that, unlike CTA and MRA, images can be reviewed in 'real time' and adjustments can therefore be made to enhance image quality prior to the completion of the test. A cost-effectiveness analysis comparing CTA or MRA with IADSA is lacking.

Although there appeared to be very little heterogeneity between studies according to CTA equipment parameters, it is possible that the accuracy of CTA compared with IADSA may further improve with advancing technology. The two earliest studies were performed using single-slice CT scanners that are now obsolete in high-income countries (Eshwar Chandra 1998; Murai 1999). The expectation therefore will be that the summary estimate of the diagnostic accuracy of CTA will continue to compare favourably with IADSA as more evidence accrues from studies benefiting from increasingly advanced technology.

\section{A U THORS, CONCLUSIONS}

\section{Implications for practice}

In conclusion, we evaluated eight studies that compared computed tomography angiography (CTA) with intra-arterial digital subtraction angiography (IADSA) and three studies that compared magnetic resonance angiography (MRA) with IADSA for the detection of intracranial vascular malformations following intracerebral haemorrhage (ICH). Studies were of variable methodological quality. Our results suggest that CTA and MRA are probably of a comparable diagnostic accuracy to IADSA in patients with $\mathrm{ICH}$. However, these estimates should be interpreted with caution because they are based on a few studies, of variable methodological quality, with small sample sizes. Neither practicality nor cost-effectiveness was evaluated in the included studies. Additional, welldesigned studies are needed to confirm whether CTA or MRA can be used as the primary imaging modality for diagnosing intracranial vascular malformations following $\mathrm{ICH}$.

\section{Implications for research}

Future research should focus on the diagnostic performance of CTA and MRA in a broad spectrum of patients following ICH. These studies should also investigate the diagnostic test accuracy of technical advances in MRA, such as high-resolution, contrast-enhanced and time-resolved techniques (Hadizadeh 2008; Taschner 2008), and in CTA, such as 4D-CTA using 320 detector row computed tomography (CT) scanners (Willems 2011; Willems 2012). Additional analyses will be required to evaluate the costeffectiveness of these tests, and their impact on patients' overall outcome. We were unable to perform a direct comparison of CTA and MRA (using IADSA as the reference standard) due to limited data, but future studies should address this issue.

Future studies should focus on the implications of false negative and false positive results. These two relative misclassification costs are rarely equal (Mallett 2012). A false negative CTA or MRA result leaves the patient at risk of recurrent haemorrhage if IADSA is not performed. Alternatively, a false positive will usually not result in harm from inappropriate treatment (surgery, radiosurgery, or embolisation) because IADSA is usually done before any procedure. Under these circumstances, a higher sensitivity at the relative expense of specificity may be optimal.

\section{ACKNOWLEDGEMENTS}

We would like to acknowledge the invaluable help of both Brenda Thomas, who assisted with the development of our search strategies for MEDLINE and EMBASE, and Dr Michael Poon for kindly translating Zhou 2012. 


\section{R E F E R E N C E S}

\section{References to studies included in this review}

Delgado Almandoz 2009 \{published and unpublished data\} Delgado Almandoz JE, Schaefer PW, Forero NP, Falla JR, Gonzalez RG, Romero JM. Diagnostic accuracy and yield of multidetector CT angiography in the evaluation of spontaneous intraparenchymal cerebral hemorrhage. American Journal of Neuroradiology 2009;30(6):1213-21.

Eshwar Chandra 1998 \{published and unpublished data\} Eshwar Chandra N, Khandelwal N, Bapuraj JR, Mathuriya SN, Vasista RK, Kak VK, et al. Spontaneous intracranial hematomas: role of dynamic CT and angiography. Acta Neurologica Scandinavica 1998;98(3):176-81.

Lummel 2012 \{published data only\}

Lummel N, Lutz J, Bruckmann H, Linn J. The value of magnetic resonance imaging for the detection of the bleeding source in non-traumatic intracerebral haemorrhages: a comparison with conventional digital subtraction angiography. Neuroradiology 2012;54(7): 673-80. [PUBMED: 21918851]

Ma 2012 \{published data only\} Ma J, Hao L, You C, Huang S, Ma L, Leong C. Accuracy of computed tomography angiography in detecting the underlying vascular abnormalities for spontaneous intracerebral hemorrhage: a comparative study and metaanalysis. Neurology India 2012;60(3):299-303.

Murai 1999 \{published and unpublished data\} Murai Y, Takagi R, Ikeda Y, Yamamoto Y, Teramoto A. Three-dimensional computerized tomography angiography in patients with hyperacute intracerebral hemorrhage. Journal of Neurosurgery 1999;91(3):424-31.

Romero 2009 \{published and unpublished data\} Romero JM, Artunduaga M, Forero NP, Delgado J, Sarfaraz $\mathrm{K}$, Goldstein JN, et al. Accuracy of CT angiography for the diagnosis of vascular abnormalities causing intraparenchymal hemorrhage in young patients. Emergency Radiology 2009;16(3):195-201.

Wong 2010 \{published and unpublished data\} Wong GK, Siu DY, Ahuja AT, King AD, Yu SC, Zhu XL, et al. Comparisons of DSA and MR angiography with digital subtraction angiography in 151 patients with subacute spontaneous intracerebral hemorrhage. Journal of Clinical Neuroscience 2010;17(5):601-5.

Wong 2011 \{published data only (unpublished sought but not used)\} Wong GK, Siu DY, Abrigo JM, Poon WS, Tsang FC, Zhu XL, et al. Computed tomographic angiography and venography for young or nonhypertensive patients with acute spontaneous intracerebral hemorrhage. Stroke 2011; 42(1):211-3.

Yeung 2009 \{published and unpublished data\} Yeung R, Ahmad T, Aviv RI, de Tilly LN, Fox AJ, Symons SP. Comparison of CTA to DSA in determining the etiology of spontaneous ICH. Canadian Journal of Neurological Sciences 2009;36(2):176-80.
Yoon 2009 \{published and unpublished data\} Yoon DY, Chang SK, Choi CS, Kim WK, Lee JH. Multidetector row CT angiography in spontaneous lobar intracerebral hemorrhage: a prospective comparison with conventional angiography. American Journal of Neuroradiology 2009;30(5):962-7.

Zhou 2012 \{published data only\} Zhou M-L, Feng J, Qu T-R. Comparison of application value of DSA and MRA in diagnosis of subacute spontaneous intracerebral hemorrhage. Journal of Jilin University Medicine Edition 2012;38(6):1209-13.

\section{References to studies excluded from this review}

Awad 1992 \{published data only\}

Awad IA, Mckenzie R, Magdinec M, Masaryk T. Application of magnetic resonance angiography to neurosurgical practice: a critical review of 150 cases. Neurological Research 1992;14(5):360-8. [PUBMED: 1362250]

Bekelis 2012 \{published data only\} Bekelis K, Desai A, Zhao W, Gibson D, Gologorsky D, Eskey $\mathrm{C}$, et al. Computed tomography angiography: improving diagnostic yield and cost effectiveness in the initial evaluation of spontaneous nonsubarachnoid intracerebral hemorrhage. Journal of Neurosurgery 2012;117 (4):761-6. [PUBMED: 22880718]

Bowen 2007 \{published data only\}

Bowen $\mathrm{BC}$. MR angiography versus $\mathrm{CT}$ angiography in the evaluation of neurovascular disease. Radiology 2007;245(2): 357-60; discussion 60-1. [PUBMED: 17940298]

Campeau 2012 \{published data only\}

Campeau NG, Huston J 3rd. Vascular disorders--magnetic resonance angiography: brain vessels. Neuroimaging Clinics of North America 2012;22(2):207-33. [PUBMED: 22548929]

Chandra 2012 \{published data only\}

Chandra T, Pukenas B, Mohan S, Melhem E. Contrastenhanced magnetic resonance angiography. Magnetic Resonance Imaging Clinics of North America 2012;20(4): 687-98. [PUBMED: 23088945]

Dammert 2004 \{published data only\} Dammert S, Krings T, Moller-Hartmann W, Ueffing E, Hans FJ, Willmes K, et al. Detection of intracranial aneurysms with multislice CT: comparison with conventional angiography. Neuroradiology 2004;46(6): 427-34. [PUBMED: 15105978]

Elhammady 2008 \{published data only\} Elhammady MS, Baskaya MK, Heros RC. Early elective surgical exploration of spontaneous intracerebral hematomas of unknown origin. Journal of Neurosurgery 2008;109(6): 1005-11. [PUBMED: 19035712]

Evans 2005 \{published data only\} Evans AL, Coley SC, Wilkinson ID, Griffiths PD. Firstline investigation of acute intracerebral hemorrhage using

Computed tomography angiography or magnetic resonance angiography for detection of intracranial vascular malformations in patients 20 with intracerebral haemorrhage (Review)

Copyright @ 2014 The Cochrane Collaboration. Published by John Wiley \& Sons, Ltd. 
dynamic magnetic resonance angiography. Acta Radiologica 2005;46(6):625-30. [PUBMED: 16334846]

Fasulakis 2003 \{published data only\}

Fasulakis S, Andronikou S. Comparison of MR angiography and conventional angiography in the investigation of intracranial arteriovenous malformations and aneurysms in children. Pediatric Radiology 2003;33(6):378-84. [PUBMED: 12768254]

Griffiths 2006 \{published data only\} Griffiths PD, Wilkinson ID. MR imaging of recent nontraumatic intracranial hemorrhage: early experience at 3 T. Neuroradiology 2006;48(4):247-54. [PUBMED: 16489468]

Gross 2012 \{published data only\}

Gross BA, Frerichs KU, Du R. Sensitivity of CT angiography, T2-weighted MRI, and magnetic resonance angiography in detecting cerebral arteriovenous malformations and associated aneurysms. Journal of Clinical Neuroscience 2012;19(8):1093-5. [PUBMED: 22705129]

Hünerbein 2003 \{published data only\} Hünerbein R, Klötzer JP, Ladanyi T, Skutta B, Mennel HD, Kailing A, et al. Spontaneous intracerebral bleeding requiring surgery - role of CT angiography in the emergency preoperative diagnosis. Klinische Neuroradiologie 2003;13: 194-202.

Kadkhodayan 2012 \{published data only\} Kadkhodayan Y, Delgado Almandoz JE, Kelly JE, Kale SP, Jagadeesan BD, Moran CJ, et al. Yield of catheter angiography in patients with intracerebral hemorrhage with and without intraventricular extension. Journal of Neurointerventional Surgery 2012;4(5):358-63. [PUBMED: 21990524]

Kamel 2013 \{published data only\} Kamel H, Navi BB, Hemphill JC 3rd. A rule to identify patients who require magnetic resonance imaging after intracerebral hemorrhage. Neurocritical Care 2013;18(1): 59-63. [PUBMED: 21761271]

Khosravani 2013 \{published data only\} Khosravani H, Mayer SA, Demchuck A, Jahromi BS, Gladstone DJ, Flaherty M, et al. Emergency noninvasive angiography for acute intracerebral hemorrhage. American Journal of Neuroradiology 2013;34(8):1481-7.

Kidwell 2010 \{published data only\} Kidwell CS, Wintermark M. The role of CT and MRI in the emergency evaluation of persons with suspected stroke. Current Neurology and Neuroscience Reports 2010;10(1): 21-8. [PUBMED: 20425222]

Lee 2007 \{published data only\} Lee HJ, Kong MH, Hong HJ, Kang DS, Song KY. The usefulness of 3D-CT angiography as a screening tool for vascular abnormalities in spontaneous ICH patients. Journal of Korean Neurosurgical Society 2007;41(4):230-5.

Leung 2012 \{published data only\}

Leung KW, Fung KH. Computed tomographic angiography findings in spontaneous intracranial haemorrhage: correlation with digital subtraction angiography. Hong Kong Journal of Radiology 2012;15(2):125-30.

Li 2013 \{published data only\}

Li X-M, Cao D-R, She D-J, Jiang F. 320-detector row $\mathrm{CT}$ angiography in diagnosis of cerebral arteriovenous malformation with hemorrhage. Chinese Journal of Medical Imaging Technology 2013;29(5):697-700.

Pott 1992 \{published data only\}

Pott M, Huber M, Assheuer J, Bewermeyer H. Comparison of MRI, CT and angiography in cerebral arteriovenous malformations. Bildgebung = Imaging 1992;59(2):98-102. [PUBMED: 1511219]

\section{Sasiadek 2000 \{published data only\}}

Sasiadek M, Hendrich B, Turek T, Kowalewski K, Maksymowicz H. Our own experience with CT angiography in early diagnosis of cerebral vascular malformations. Neurologia i Neurochirurgia Polska 2000;34(6 Suppl):48-55. [PUBMED: 11452855]

Sasiadek 2002 \{published data only\}

Sasiadek M, Kowalewski K, Turek T, Hendrich B, Podkowa $\mathrm{J}$, Maksymowicz $\mathrm{H}$. Efficiency of CT-angiography in the diagnosis of intracranial aneurysms. Medical Science Monitor 2002;8(6):MT99-MT104. [PUBMED: 12070447]

Sha 2008 \{published data only\}

Sha L, Bian J, Cheng S-L, Huang D, Dong J-D. Compared study of diagnostic value of CE-MRA and TOF-MRA in cerebral and cervical aneurysm. Journal of Dalian Medical University 2008;30(1):56-60.

Truwit 2007 \{published data only\} Truwit CL. CT angiography versus MR angiography in the evaluation of acute neurovascular disease. Radiology 2007; 245(2):362-6. [PUBMED: 17940299]

Wijman 2012 \{published data only\} Wijman CA, Snider RW, Venkatasubramanian C, FinleyCaulfield A, Buckwalter M, Eyngorn I, et al. Diagnostic accuracy of MRI in spontaneous intra-cerebral hemorrhage (DASH) - final results. Stroke 2012;43:A105.

Zheng 2012 \{published data only\}

Zheng T, Wang S, Barras C, Davis S, Yan B. Vascular imaging adds value in investigation of basal ganglia hemorrhage. Journal of Clinical Neuroscience 2012;19(2): 277-80. [PUBMED: 22118795]

\section{Additional references}

\section{Al-Shahi 2001}

Al-Shahi R, Warlow C. A systematic review of the frequency and prognosis of arteriovenous malformations of the brain in adults. Brain 2001;124(Pt 10):1900-26. [PUBMED: 11571210]

\section{Al-Shahi Salman 2009}

Al-Shahi Salman R, Labovitz DL, Stapf C. Spontaneous intracerebral haemorrhage. BMJ 2009;339:b2586. [PUBMED: 19633038]

\section{Bossuyt 2003}

Bossuyt PM, Reitsma JB, Bruns DE, Gatsonis CA, Glasziou PP, Irwig LM, et al. Towards complete and accurate 
reporting of studies of diagnostic accuracy: the STARD initiative. BMJ 2003;326(7379):41-4. [PUBMED: 12511463]

\section{Brazzelli 2009}

Brazzelli M, Sandercock PA, Chappell FM, Celani MG, Righetti E, Arestis N, et al. Magnetic resonance imaging versus computed tomography for detection of acute vascular lesions in patients presenting with stroke symptoms. Cochrane Database of Systematic Reviews 2009, Issue 4. [DOI: 10.1002/14651858.CD007424.pub2]

\section{Chappell 2003}

Chappell ET, Moure FC, Good MC. Comparison of computed tomographic angiography with digital subtraction angiography in the diagnosis of cerebral aneurysms: a metaanalysis. Neurosurgery 2003;52(3):624-31; discussion 6301. [PUBMED: 12590688]

\section{Cordonnier 2010}

Cordonnier C, Klijn CJ, van Beijnum J, Al-Shahi Salman R. Radiological investigation of spontaneous intracerebral hemorrhage: systematic review and trinational survey. Stroke 2010;41(4):685-90. [PUBMED: 20167915]

\section{Deeks 2005}

Deeks JJ, Macaskill P, Irwig L. The performance of tests of publication bias and other sample size effects in systematic reviews of diagnostic test accuracy was assessed. Journal of Clinical Epidemiology 2005;58(9):882-93. [PUBMED: 16085191]

\section{Gluud 2005}

Gluud C, Gluud LL. Evidence based diagnostics. BMJ (Clinical research edition) 2005;330(7493):724-6. [PUBMED: 15790646]

\section{Hadizadeh 2008}

Hadizadeh DR, von Falkenhausen M, Gieseke J, Meyer B, Urbach H, Hoogeveen R, et al. Cerebral arteriovenous malformation: Spetzler-Martin classification at subsecondtemporal-resolution four-dimensional MR angiography compared with that at DSA. Radiology 2008;246(1): 205-13.

\section{Hino 1998}

Hino A, Fujimoto M, Yamaki T, Iwamoto Y, Katsumori T. Value of repeat angiography in patients with spontaneous subcortical hemorrhage. Stroke 1998;29(12):2517-21. [PUBMED: 9836762]

\section{Lijmer 1999}

Lijmer JG, Mol BW, Heisterkamp S, Bonsel GJ, Prins MH, van der Meulen JH, et al. Empirical evidence of designrelated bias in studies of diagnostic tests. JAMA 1999;282 (11):1061-6. [PUBMED: 10493205]

\section{Lovelock 2007}

Lovelock CE, Molyneux AJ, Rothwell PM. Change in incidence and aetiology of intracerebral haemorrhage in Oxfordshire, UK, between 1981 and 2006: a populationbased study. Lancet Neurology 2007;6(6):487-93. [PUBMED: 17509483]

\section{Macaskill 2010}

Macaskill P, Gatsonis C, Deeks JJ, Harbord RM, Takwoingi Y. Chapter 10: Analysing and presenting results. In: Deeks JJ, Bossuyt PM, Gatsonis C editor(s). Cochrane Handbook for Systematic Reviews of Diagnostic Test Accuracy Version 1.0. The Cochrane Collaboration, 2010.

\section{Mallett 2012}

Mallett S, Halligan S, Thompson M, Collins GS, Altman DG. Interpreting diagnostic accuracy studies for patient care. BMJ 2012;345:e3999. [PUBMED: 22750423]

\section{Manninen 2012}

Manninen AL, Isokangas JM, Karttunen A, Siniluoto T, Nieminen MT. A comparison of radiation exposure between diagnostic CTA and DSA examinations of cerebral and cervicocerebral vessels. American Journal of Neuroradiology 2012;33(11):2038-42. [PUBMED: 22700752]

\section{RevMan 2012}

The Nordic Cochrane Centre, The Cochrane Collaboration. Review Manager (RevMan). 5.2. Copenhagen: The Nordic Cochrane Centre, The Cochrane Collaboration, 2012.

\section{Rutjes 2006}

Rutjes AW, Reitsma JB, Di Nisio M, Smidt N, van Rijn JC, Bossuyt PM. Evidence of bias and variation in diagnostic accuracy studies. Canadian Medical Association Journal 2006;174(4):469-76. [PUBMED: 16477057]

\section{Scott 2009}

Scott RM, Smith ER. Moyamoya disease and moyamoya syndrome. New England Journal of Medicine 2009;360(12): 1226-37. [PUBMED: 19297575]

StataCorp 2011

StataCorp LP. Stata Statistical Software: Release 12. College Station, TX, USA: StataCorp LP, 2011.

\section{Taschner 2008}

Taschner CA, Gieseke J, Le Thuc V, Rachdi H, Reyns N, Gauvrit JY, et al. Intracranial arteriovenous malformation: time-resolved, contrast-enhanced MR angiography with combination of parallel imaging, keyhole acquisition, and k-space sampling techniques at 1.5 T. Radiology 2008;246 (3):871-9.

\section{Van Asch 2010}

Van Asch CJ, Luitse MJ, Rinkel GJ, Van der Tweel I, Algra A, Klijn CJ. Incidence, case fatality, and functional outcome of intracerebral haemorrhage over time, according to age, sex, and ethnic origin: a systematic review and metaanalysis. Lancet Neurology 2010;9(2):167-76. [PUBMED: 20056489]

Van Beijnum 2009

Van Beijnum J, Lovelock CE, Cordonnier C, Rothwell PM, Klijn CJ, Al-Shahi Salman R. Outcome after spontaneous and arteriovenous malformation-related intracerebral haemorrhage: population-based studies. Brain 2009;132 (Pt 2):537-43. [PUBMED: 19042932]

\section{Van Gelder 2003}

Van Gelder JM. Computed tomographic angiography for detecting cerebral aneurysms: implications of aneurysm size 
distribution for the sensitivity, specificity, and likelihood ratios. Neurosurgery 2003;53(3):597-605; discussion 605-6. [PUBMED: 12943576]

\section{Westerlaan 2011}

Westerlaan HE, Van Dijk MJ, Jansen-van der Weide MC, De Groot JC, Groen RJ, Mooij JJ, et al. Intracranial aneurysms in patients with subarachnoid hemorrhage: CT angiography as a primary examination tool for diagnosis-systematic review and meta-analysis. Radiology 2011;258 (1):134-45. [PUBMED: 20935079]

\section{White 2000}

White PM, Wardlaw JM, Easton V. Can noninvasive imaging accurately depict intracranial aneurysms? A systematic review. Radiology 2000;217(2):361-70. [PUBMED: 11058629]

Whiting 2003

Whiting P, Rutjes AW, Reitsma JB, Bossuyt PM, Kleijnen J. The development of QUADAS: a tool for the quality assessment of studies of diagnostic accuracy included in systematic reviews. BMC Medical Research Methodology 2003;3:25. [PUBMED: 14606960]

\section{Willems 2011}

Willems PW, Brouwer PA, Barfett JJ, terBrugge KG, Krings T. Detection and classification of cranial dural arteriovenous fistulas using 4D-CT angiography: initial experience. American Journal of Neuroradiology 2011;32:49-53.

\section{Willems 2012}

Willems PW, Taeshineetanakul P, Schenk B, Brouwer PA, terBrugge KG, Krings T. The use of 4D-CTA in the diagnostic work-up of brain arteriovenous malformations. Neuroradiology 2012;54:123-31.

\section{Wong 2012}

Wong GK, Siu DY, Abrigo JM, Ahuja AT, Poon WS. Computed tomographic angiography for patients with acute spontaneous intracerebral hemorrhage. Journal of Clinical Neuroscience 2012;19(4):498-500. [PUBMED: 22321368]

* Indicates the major publication for the study 


\title{
CHARACTERISTICS OF STUDIES
}

\section{Characteristics of included studies [ordered by study ID]}

\author{
Delgado Almandoz 2009
}

Clinical features and settings

The study enrolled consecutive patients $\geq 18$ years of age presenting to a tertiary care emergency centre in Boston, USA, from 1 January 2000 to 1 November 2008, with evidence of intraparenchymal haemorrhage on CT. Patients had to be evaluated with CTA within 24 hours of presentation. Patients with associated subarachnoid haemorrhage in the basal cisterns, loss of grey-white matter differentiation in a vascular territory suggesting a pre-established acute ischaemic stroke, a known intracranial vascular malformation or mass lesion, or known probable cerebral amyloid angiopathy according to Boston criteria were excluded

Participants

775 patients were screened of which 210 were eligible and enrolled. Mean participant age was not documented. The gender breakdown was not provided. No details were available about co-morbidities. No details were provided about ICH location or extension of blood into other intracranial compartments

Study design $\quad$ Retrospective study of consecutive patients

Target condition and reference standard(s) The reference standards were IADSA and intraoperative and pathological findings. Data exclusive to IADSA were obtained. IADSA equipment and technical specifications were not documented. A positive result was a vascular abnormality accounting for the haemorrhage

Index and comparator tests

The index test was CTA performed using a 16- or 64-slice LightSpeed GE Healthcare helical CT scanner. The base of the $\mathrm{C} 1$ vertebrae to the vertex was scanned using a pitch of $0.5,1.25 \mathrm{~mm}$ slice thickness, and a field of view of $22 \mathrm{~cm}$. Non-ionic contrast material (65 to $85 \mathrm{~mL}$ ) was administered by power injector at 4 to $5 \mathrm{~mL} / \mathrm{s}$ with either a fixed 25-second delay between onset of contrast material injection and start of scanning (or a delay of 40 seconds if the participant had atrial fibrillation) or by SmartPrep automatic contrast-bolus triggering technique. A positive result was defined as any underlying vascular abnormality accounting for the haemorrhage

Follow-up

The study authors did not state whether there were any study withdrawals. The authors did not report whether there were any instances of uninterpretable images. The authors did not report whether any participants suffered an adverse event

Level of expertise of those interpreting the index test

The CTA source and maximum intensity projection images were reviewed by 2 neuroradiologists blinded to the participant's clinical information

Notes

The resulting $1.25 \mathrm{~mm}$ thick axial CTA source images were digitally archived and standard maximum intensity projection images of the major intracranial vessels were created by the 3-D laboratory

Table of Methodological Quality

Computed tomography angiography or magnetic resonance angiography for detection of intracranial vascular malformations in patients 
Delgado Almandoz 2009 (Continued)

\begin{tabular}{l|l|l}
\hline Item & Authors' judgement & Description \\
\hline $\begin{array}{l}\text { Representative spectrum? } \\
\text { No }\end{array}$ & Unclear & $\begin{array}{l}\text { Patients had to be evaluated with CTA } \\
\text { within 24 hours of presentation to be eligi- } \\
\text { ble for the study }\end{array}$ \\
\hline $\begin{array}{l}\text { All tests } \\
\text { bceptable reference standard? }\end{array}$ & $\begin{array}{l}\text { The reference standard was IADSA and was } \\
\text { described in sufficient detail to replicate. } \\
\text { However, the level of expertise of those in- } \\
\text { terpreting the images was not documented }\end{array}$ \\
\hline
\end{tabular}

Acceptable delay between tests? No

All tests

Partial verification avoided? No

All tests

\begin{tabular}{l|l} 
& \\
\hline $\begin{array}{l}\text { Differential verification avoided? } \\
\text { All tests }\end{array}$ & Yes
\end{tabular}

Yes

\begin{tabular}{l|l}
\hline \\
$\begin{array}{l}\text { Incorporation avoided? } \\
\text { All tests }\end{array}$ \\
\hline
\end{tabular}

Reference standard results blinded? Unclear

All tests

\begin{tabular}{l|l}
\hline Index test results blinded? & Yes \\
All tests
\end{tabular}

Yes

Relevant clinical information? No

All tests

No

\begin{tabular}{l|l} 
& \\
\hline $\begin{array}{l}\text { Uninterpretable results reported? } \\
\text { All tests }\end{array}$ & Unclear \\
\hline $\begin{array}{l}\text { Withdrawals explained? } \\
\text { All tests }\end{array}$ & Yes \\
\hline $\begin{array}{l}\text { Index test interpreted by an expert? } \\
\text { All tests }\end{array}$ & Yes \\
\hline
\end{tabular}

The authors did not report the delay between the CTA and IADSA

This is a retrospective study and, in routine practice, the CTA result would influence the decision to proceed to either to IADSA or straight to surgery

IADSA, surgical findings, and pathology were used as reference standards. However, data exclusive to IADSA as a reference standard were obtained from the authors

CTA did not form a part of the reference standard

The reference standard was the IADSA final report. It is not clear whether those interpreting the IADSA images were privy to results of the CTA scans

Those interpreting the CTA were blinded to the IADSA result

Those interpreting the CTA images were blinded to all relevant clinical information including the participant's clinical condition and other imaging reports

No comment was made about uninterpretable scans

All participants could be accounted for in the paper

The CTA source and MIP images were reviewed by two neuroradiologists 

acute, spontaneous ICH over a 5-year period from 1990 to 1995 . Hypertensive patients with haemorrhage in the thalamus, putamen, internal capsule, and the cerebellum were excluded

Participants

It is unclear how many patients were screened for inclusion or were potentially eligible for enrolment. 45 participants were enrolled. Females comprised 36\% (16/45) of the total population. Mean or median age was not documented; age range was 3 to 75 years old. It is unclear how many had a prior intracranial haemorrhage. ICH was lobar in 38 $(84 \%)$ cases, deep in $4(9 \%)$ cases, and infratentorial in $3(7 \%)$ cases. Mean ICH size at presentation was not documented

Study design

Prospective case series. All participants underwent dynamic CT (CTA) and 44 of 45 underwent IADSA

Target condition and reference standard(s) The reference standards were IADSA and surgical findings. IADSA equipment and technical specifications were not documented. A positive result was a vascular abnormality accounting for the haemorrhage

Index and comparator tests

The index test was a dynaCT. All were performed using either a Siemens Somatom HiQ S Scanner or a Shimadzu SCT 2000T. These were single-slice, non-spiral scanners. Technical specifications were not documented. The study covered the Circle of Willis and the region of the haematoma. A positive result was a vascular abnormality accounting for the haemorrhage

Follow-up

Study withdrawals and exclusions were explained. There was no statement made about uninterpretable images. There was no statement regarding whether any adverse effects occurred

Level of expertise of those interpreting the The level of experience of those interpreting the dynaCT scans was not documented index test

Notes

There was no description of post-processing reconstruction of angiographic images

Table of Methodological Quality

\begin{tabular}{|c|c|c|}
\hline Item & Authors' judgement & Description \\
\hline Representative spectrum? & No & $\begin{array}{l}\text { Hypertensive patients with haemorrhage in } \\
\text { the thalamus, putamen, internal capsule, } \\
\text { and cerebellum were excluded }\end{array}$ \\
\hline $\begin{array}{l}\text { Acceptable reference standard? } \\
\text { All tests }\end{array}$ & Unclear & $\begin{array}{l}\text { The technical specifications and the back- } \\
\text { ground of those interpreting the IADSA } \\
\text { was not documented. There was no de- } \\
\text { scription of the extent to which the arterial } \\
\text { territories that surrounded the haematoma } \\
\text { were evaluated }\end{array}$ \\
\hline
\end{tabular}


Eshwar Chandra 1998 (Continued)

\begin{tabular}{|c|c|c|}
\hline $\begin{array}{l}\text { Acceptable delay between tests? } \\
\text { All tests }\end{array}$ & No & The delay between tests was not reported \\
\hline $\begin{array}{l}\text { Partial verification avoided? } \\
\text { All tests }\end{array}$ & Yes & CTA did not determine who got IADSA \\
\hline $\begin{array}{l}\text { Differential verification avoided? } \\
\text { All tests }\end{array}$ & Yes & $\begin{array}{l}\text { IADSA and histopathological findings } \\
\text { were used as reference standards. Data ex- } \\
\text { clusive to IADSA could be extracted }\end{array}$ \\
\hline $\begin{array}{l}\text { Incorporation avoided? } \\
\text { All tests }\end{array}$ & Yes & $\begin{array}{l}\text { dynaCT did not form a part of the reference } \\
\text { standard }\end{array}$ \\
\hline $\begin{array}{l}\text { Reference standard results blinded? } \\
\text { All tests }\end{array}$ & Unclear & $\begin{array}{l}\text { There was no statement about whether } \\
\text { those interpreting the IADSA images were } \\
\text { blinded to the results of the dynaCT test }\end{array}$ \\
\hline $\begin{array}{l}\text { Index test results blinded? } \\
\text { All tests }\end{array}$ & Unclear & $\begin{array}{l}\text { There was no statement about whether } \\
\text { those interpreting the dynaCT test were } \\
\text { blinded to the results of the IADSA }\end{array}$ \\
\hline $\begin{array}{l}\text { Relevant clinical information? } \\
\text { All tests }\end{array}$ & Unclear & $\begin{array}{l}\text { There was no statement about whether } \\
\text { those interpreting the IADSA and dyn- } \\
\text { aCT were provided with all relevant clin- } \\
\text { ical information apart from the results of } \\
\text { the competing test }\end{array}$ \\
\hline $\begin{array}{l}\text { Uninterpretable results reported? } \\
\text { All tests }\end{array}$ & Unclear & $\begin{array}{l}\text { There was no statement about whether un- } \\
\text { interpretable results were encountered }\end{array}$ \\
\hline $\begin{array}{l}\text { Withdrawals explained? } \\
\text { All tests }\end{array}$ & Yes & $\begin{array}{l}\text { All participants could be accounted for in } \\
\text { the paper }\end{array}$ \\
\hline $\begin{array}{l}\text { Index test interpreted by an expert? } \\
\text { All tests }\end{array}$ & Unclear & $\begin{array}{l}\text { The level of experience of those interpret- } \\
\text { ing the dynaCT scans was not documented }\end{array}$ \\
\hline
\end{tabular}

Lummel 2012

Clinical features and settings

Patients with acute ICH identified from an electronic in-hospital database in Munich, Germany, were included if they had MRI/A imaging within 20 days of symptom onset and had MRI/A and IADSA image quality that was sufficient for evaluation. Patients with traumatic ICH were excluded. However, in the majority of cases, MRA was only performed if CTA was 'normal', meaning that this is likely a dilute sample of patients with vascular malformations

Participants

120 patients were screened, 67 were eligible, and all were enrolled. Mean age was 53.4 years (range 14 to 82 years of age). There were 23 (34\%) females and 44 (66\%) males. No details were provided about co-morbidities. ICH was associated with intraventricular

Computed tomography angiography or magnetic resonance angiography for detection of intracranial vascular malformations in patients with intracerebral haemorrhage (Review)

Copyright $(2014$ The Cochrane Collaboration. Published by John Wiley \& Sons, Ltd. 
haemorrhage in 8 cases and subarachnoid haemorrhage in 5 cases. Haemorrhage was lobar in 36 cases, basal ganglial in 13 cases, and infratentorial in 18 cases

Study design

Retrospective case series. All participants underwent both MRA and IADSA although it appears that IADSA preceded MRA in all cases

Target condition and reference standard(s) The reference standard was IADSA. The equipment was not described other than stating that a Biplanar Neurostar DSA system was used. The authors did not provide a formal definition but stated that their aim was to identify vascular malformations and other bleeding sources in $\mathrm{ICH}$ patients

Index and comparator tests

The index test was MRA. All scans were performed using either a Magnetom Symphony 1.5T unit or a Sign HDxt 3T unit. Magnet strength was either 1.5 or $3 \mathrm{~T}$. Depending on the participant, sequences included T1, contrast-enhanced $\mathrm{T} 1, \mathrm{~T} 2$, proton density, FLAIR, T2*, and DWI. All 67 participants had time of flight imaging and 40 participants had contrast-enhanced imaging. The study authors did not provide a formal definition but stated that their aim was to identify vascular malformations and other bleeding sources in ICH patients

Follow-up

Study withdrawals and exclusions were explained. There was no statement made about uninterpretable images. There was no statement regarding whether any adverse effects occurred

Level of expertise of those interpreting the MRA images were evaluated independently by 2 neuroradiologists index test

Notes

IADSA images were evaluated by the same 2 neuroradiologists. There was no description of post-processing reconstruction of angiographic images. Interrater reliability for the detection of an IADSA positive lesion was excellent ( $\mathrm{kappa}=0.93)$

Table of Methodological Quality

\begin{tabular}{|c|c|c|}
\hline Item & Authors' judgement & Description \\
\hline Representative spectrum? & No & $\begin{array}{l}\text { All patients with non-traumatic ICH who } \\
\text { had an MRI performed within } 20 \text { days of } \\
\text { symptom onset. However, in the majority } \\
\text { of cases, MRA was only performed if CTA } \\
\text { was 'normal', meaning that this is likely a } \\
\text { dilute sample of patients with vascular mal- } \\
\text { formations }\end{array}$ \\
\hline $\begin{array}{l}\text { Acceptable reference standard? } \\
\text { All tests }\end{array}$ & Unclear & $\begin{array}{l}\text { The technical specifications of the IADSA } \\
\text { were not documented. There was no de- } \\
\text { scription of the extent to which the arterial } \\
\text { territories that surrounded the haematoma } \\
\text { were evaluated }\end{array}$ \\
\hline
\end{tabular}


Lummel 2012 (Continued)

\begin{tabular}{|c|c|c|}
\hline $\begin{array}{l}\text { Acceptable delay between tests? } \\
\text { All tests }\end{array}$ & No & The delay between tests was not reported \\
\hline $\begin{array}{l}\text { Partial verification avoided? } \\
\text { All tests }\end{array}$ & No & $\begin{array}{l}\text { The study was retrospective and in routine } \\
\text { practice it would be expected that MRA } \\
\text { would influence the choice to proceed to } \\
\text { IADSA }\end{array}$ \\
\hline $\begin{array}{l}\text { Differential verification avoided? } \\
\text { All tests }\end{array}$ & Yes & $\begin{array}{l}\text { Every participant underwent IADSA as the } \\
\text { reference standard }\end{array}$ \\
\hline $\begin{array}{l}\text { Incorporation avoided? } \\
\text { All tests }\end{array}$ & Yes & $\begin{array}{l}\text { MRA did not form a part of the reference } \\
\text { standard }\end{array}$ \\
\hline $\begin{array}{l}\text { Reference standard results blinded? } \\
\text { All tests }\end{array}$ & No & $\begin{array}{l}\text { The same } 2 \text { neuroradiologists interpreted } \\
\text { the IADSA images in the presence of } \\
\text { all participant information following their } \\
\text { analysis of MRA images }\end{array}$ \\
\hline $\begin{array}{l}\text { Index test results blinded? } \\
\text { All tests }\end{array}$ & Yes & $\begin{array}{l}\text { MRA was interpreted by } 2 \text { neuroradiolo- } \\
\text { gists blinded to all participant information } \\
\text { including IADSA results }\end{array}$ \\
\hline $\begin{array}{l}\text { Relevant clinical information? } \\
\text { All tests }\end{array}$ & No & $\begin{array}{l}\text { MRA was interpreted by } 2 \text { neuroradiolo- } \\
\text { gists blinded to all participant information }\end{array}$ \\
\hline $\begin{array}{l}\text { Uninterpretable results reported? } \\
\text { All tests }\end{array}$ & Unclear & $\begin{array}{l}\text { There was no statement about whether un- } \\
\text { interpretable results were encountered }\end{array}$ \\
\hline $\begin{array}{l}\text { Withdrawals explained? } \\
\text { All tests }\end{array}$ & Yes & $\begin{array}{l}\text { All participants could be accounted for in } \\
\text { the paper }\end{array}$ \\
\hline $\begin{array}{l}\text { Index test interpreted by an expert? } \\
\text { All tests }\end{array}$ & Yes & $\begin{array}{l}\text { MRA was interpreted by } 2 \text { neuroradiolo- } \\
\text { gists }\end{array}$ \\
\hline
\end{tabular}

Ma 2012

Clinical features and settings

Participants
Patients with acute ICH admitted to West China Hospital in Sichuan, China, were included if they were non-hypertensive (defined by medical history or clinical evidence of normal blood pressure) and were between the ages of 18 and 45 years. Patients with a traumatic ICH or primarily subarachnoid haemorrhage were excluded

436 patients were screened, 97 were eligible, and 92 were enrolled. 5 eligible patients were excluded because of renal failure $(n=1)$ or a brain tumour $(n=4)$. Data regarding age and gender were not provided. No details were provided about co-morbidities. No details were provided about ICH location or extension of blood into other intracranial compartments 


\section{Ma 2012 (Continued)}

\begin{tabular}{ll}
\hline Study design & Prospective case series. All participants underwent both CTA and IADSA \\
\hline Target condition and reference standard(s) & $\begin{array}{l}\text { The reference standard was IADSA. The equipment was not described other than stating } \\
\text { a GE LCV + Advantx system was used. A positive test result was defined as a 'vascular } \\
\text { lesion' }\end{array}$ \\
\hline Index and comparator tests & $\begin{array}{l}\text { The index test was CTA. All scans were performed using a GE LightSpeed VCT } 64 \\
\text { scanner. The study covered 'rostral from C-2'. The parameters used included } 0.625 \mathrm{~mm} \\
\text { slice thickness every 0.6 mm and a pitch of } 513: 1 . \text { A total of } 125 \mathrm{~mL} \text { of Omnipaque } \\
\text { 300 was administered intravenously at a rate of } 4.0 \text { to } 5.0 \mathrm{~mL} / \mathrm{s} \text { using a 15-second prep } \\
\text { delay. A positive test result was defined as a 'vascular lesion' }\end{array}$ \\
\hline Follow-up & $\begin{array}{l}\text { Study withdrawals and exclusions were explained. There was no statement made about } \\
\text { uninterpretable images. There was no statement regarding whether any adverse effects } \\
\text { occurred }\end{array}$ \\
\hline
\end{tabular}

Level of expertise of those interpreting the CTA images were evaluated independently by 2 neuroradiologists index test

Notes

There was no description of post-processing reconstruction of angiographic images. IADSA images were interpreted by 2 endovascular neuroradiologists

Table of Methodological Quality

\begin{tabular}{|c|c|c|}
\hline Item & Authors' judgement & Description \\
\hline Representative spectrum? & No & $\begin{array}{l}\text { Patients over the age of } 45 \text { and those with } \\
\text { pre-existing hypertension were excluded }\end{array}$ \\
\hline $\begin{array}{l}\text { Acceptable reference standard? } \\
\text { All tests }\end{array}$ & Unclear & $\begin{array}{l}\text { The technical specifications of the IADSA } \\
\text { were not documented. There was no de- } \\
\text { scription of the extent to which the arterial } \\
\text { territories that surrounded the haematoma } \\
\text { were evaluated }\end{array}$ \\
\hline $\begin{array}{l}\text { Acceptable delay between tests? } \\
\text { All tests }\end{array}$ & No & The delay between tests was not reported \\
\hline $\begin{array}{l}\text { Partial verification avoided? } \\
\text { All tests }\end{array}$ & Yes & $\begin{array}{l}\text { CTA did not determine who underwent } \\
\text { IADSA }\end{array}$ \\
\hline $\begin{array}{l}\text { Differential verification avoided? } \\
\text { All tests }\end{array}$ & Yes & $\begin{array}{l}\text { Every participant underwent IADSA as the } \\
\text { reference standard }\end{array}$ \\
\hline $\begin{array}{l}\text { Incorporation avoided? } \\
\text { All tests }\end{array}$ & Yes & $\begin{array}{l}\text { CTA did not form a part of the reference } \\
\text { standard }\end{array}$ \\
\hline
\end{tabular}


Ma 2012 (Continued)

\begin{tabular}{l|l|l}
\hline $\begin{array}{l}\text { Reference standard results blinded? } \\
\text { All tests }\end{array}$ & Yes & $\begin{array}{l}\text { IADSA was reviewed by } 2 \text { endovascular } \\
\text { neuroradiologists blinded to clinical and } \\
\text { CTA data }\end{array}$ \\
\hline $\begin{array}{l}\text { Index test results blinded? } \\
\text { All tests }\end{array}$ & Yes & $\begin{array}{l}\text { CTA was reviewed by } 2 \text { neuroradiologists } \\
\text { blinded to clinical information }\end{array}$ \\
\hline $\begin{array}{l}\text { Relevant clinical information? } \\
\text { All tests }\end{array}$ & No & IADSA and CTA were read blinded to all \\
\hline $\begin{array}{l}\text { Uninterpretable results reported? } \\
\text { All tests }\end{array}$ & Unclear & $\begin{array}{l}\text { There was no statement about whether un- } \\
\text { interpretable results were encountered }\end{array}$ \\
\hline $\begin{array}{l}\text { Withdrawals explained? } \\
\text { All tests }\end{array}$ & Yes & $\begin{array}{l}\text { All participants could be accounted for in } \\
\text { the paper }\end{array}$ \\
\hline $\begin{array}{l}\text { Index test interpreted by an expert? } \\
\text { All tests }\end{array}$ & Yes & CTA was interpreted by 2 neuroradiolo- \\
\hline
\end{tabular}

Murai 1999

Clinical features and settings

Patients referred to a tertiary care referral centre in Tokyo, Japan, for investigation of spontaneous ICH. Patients were included if they had an initial CT scan performed within 12 hours of symptom onset and a second CT within 24 hours of onset, a 3D-CTA performed within 12 hours of symptom onset, and IADSA performed in the 'chronic stage'. Patients who were clinically unstable or who had a history of chronic renal failure or an allergic reaction to iodine were excluded

Participants

92 patients were screened, and 31 were eligible and enrolled. The mean age was 56 years (range 34 to 74$)$. Over half $(17 / 31 ; 55 \%)$ were male. No details were provided about co-morbidities. No details were provided about ICH location or extension of blood into other intracranial compartments

Study design

Prospective case series. All participants underwent both the index and reference standard

Target condition and reference standard(s) The reference standard was IADSA. The equipment used to perform IADSA was not described. 1- or 2-vessel angiography was performed using cut-film technique. A positive test result was the presence of a vascular abnormality as the cause of haemorrhage

Index and comparator tests

The index test was CTA. All scans were performed using a Hitachi W 3000 AD helical single-slice scanner. The study covered the Circle of Willis and the region of the haematoma. The parameters used included $1 \mathrm{~mm}$ slice thickness, a 512 x 512 matrix, a pitch of 1 , and a $21 \mathrm{~cm}$ field of view. Participants were scanned from the posterior margin of the haematoma through superior margin including the middle cerebral artery and Circle of Willis. A total of $100 \mathrm{~mL}$ of Iomeprol $(350 \mathrm{mg}$ iodine $/ \mathrm{mL}$ ) was administered intravenously at $2 \mathrm{~mL} / \mathrm{s}$ using a 25 -second pre-scanning delay. A positive result was the identification of a vascular abnormality as the cause of haemorrhage

Computed tomography angiography or magnetic resonance angiography for detection of intracranial vascular malformations in patients $3 \mathrm{I}$ with intracerebral haemorrhage (Review)

Copyright $\Subset 2014$ The Cochrane Collaboration. Published by John Wiley \& Sons, Ltd. 


\section{Murai 1999 (Continued)}

Follow-up

Study withdrawals and exclusions were explained. There was no statement made about uninterpretable images. There was no statement regarding whether any adverse effects occurred

Level of expertise of those interpreting the CTA images were evaluated by a neuroradiologist index test

$\begin{array}{ll}\text { Notes } & \text { CTA images were reconstructed into } 3 \text { dimensions using a volume-rendered technique } \\ \text { through 'standard scanner software'. We were able to reclassify cases of moya-moya as } \\ \text { 'negatives' after receiving data from the study authors }\end{array}$

Table of Methodological Quality

\begin{tabular}{|c|c|c|}
\hline Item & Authors' judgement & Description \\
\hline Representative spectrum? & No & $\begin{array}{l}\text { The study population was restricted to only } \\
\text { those patients undergoing CT scans at both } \\
12 \text { and } 24 \text { hours following symptom onset } \\
\text { and a CTA within } 12 \text { hours of symptom } \\
\text { onset }\end{array}$ \\
\hline $\begin{array}{l}\text { Acceptable reference standard? } \\
\text { All tests }\end{array}$ & Unclear & $\begin{array}{l}\text { The reference standard was IADSA and was } \\
\text { described in sufficient detail to replicate. } \\
\text { However, the level of expertise of those in- } \\
\text { terpreting the images was not documented }\end{array}$ \\
\hline $\begin{array}{l}\text { Acceptable delay between tests? } \\
\text { All tests }\end{array}$ & No & $\begin{array}{l}\text { The authors did not indicate the delay be- } \\
\text { tween the CTA and IADSA }\end{array}$ \\
\hline $\begin{array}{l}\text { Partial verification avoided? } \\
\text { All tests }\end{array}$ & No & $\begin{array}{l}\text { The CTA result determined when the par- } \\
\text { ticipant underwent IADSA }\end{array}$ \\
\hline $\begin{array}{l}\text { Differential verification avoided? } \\
\text { All tests }\end{array}$ & Yes & $\begin{array}{l}\text { All participants underwent both a CTA and } \\
\text { an IADSA }\end{array}$ \\
\hline $\begin{array}{l}\text { Incorporation avoided? } \\
\text { All tests }\end{array}$ & Yes & $\begin{array}{l}\text { CTA did not form a part of the reference } \\
\text { standard }\end{array}$ \\
\hline $\begin{array}{l}\text { Reference standard results blinded? } \\
\text { All tests }\end{array}$ & Unclear & $\begin{array}{l}\text { The authors did not state whether the } \\
\text { IADSA images were interpreted blinded to } \\
\text { the CTA result }\end{array}$ \\
\hline $\begin{array}{l}\text { Index test results blinded? } \\
\text { All tests }\end{array}$ & Unclear & $\begin{array}{l}\text { The authors did not state whether the } \\
\text { CTA images were interpreted blinded to } \\
\text { the IADSA result }\end{array}$ \\
\hline $\begin{array}{l}\text { Relevant clinical information? } \\
\text { All tests }\end{array}$ & Unclear & $\begin{array}{l}\text { The authors did not state whether all rou- } \\
\text { tine clinical information apart from the re- } \\
\text { sult of the competing test was available to }\end{array}$ \\
\hline
\end{tabular}

Computed tomography angiography or magnetic resonance angiography for detection of intracranial vascular malformations in patients 32 with intracerebral haemorrhage (Review)

Copyright $(2014$ The Cochrane Collaboration. Published by John Wiley \& Sons, Ltd. 
Murai 1999 (Continued)

those interpreting the CTA and IADSA images

\begin{tabular}{|c|c|c|}
\hline $\begin{array}{l}\text { Uninterpretable results reported? } \\
\text { All tests }\end{array}$ & Unclear & $\begin{array}{l}\text { The authors did not state whether uninter- } \\
\text { pretable images were encountered }\end{array}$ \\
\hline $\begin{array}{l}\text { Withdrawals explained? } \\
\text { All tests }\end{array}$ & Yes & $\begin{array}{l}\text { The authors explained study exclusions. All } \\
\text { enrolled participants were accounted for in } \\
\text { the analysis }\end{array}$ \\
\hline
\end{tabular}

Index test interpreted by an expert? Yes

All tests

A neuroradiologist reviewed all CTA images

Romero 2009

Clinical features and settings

Participants

Study design

Target condition and reference standard(s) The reference standard was IADSA and surgical and pathological findings. Data exclu-

Index and comparator tests sive to IADSA were obtained. IADSA equipment and technical specifications were not documented but was there were appropriate references to the literature that would enable replication of the procedure. A positive result was a vascular abnormality accounting for the haemorrhage

This study enrolled patients from a tertiary care referral centre in Boston, USA, with acute, spontaneous ICH who underwent CTA over a 5-year period from 2002 to 2007. Patients with known vascular anomalies, known brain neoplasms, those with imaging findings suggestive of ischaemic stroke on admission, or those with subarachnoid haemorrhage within the Sylvian fissures or basal cisterns, or both, were excluded

80 patients were screened for inclusion. 43 patients were eligible and all were enrolled. There were no study withdrawals. Females comprised 54\% (23/43) of the total population. The mean age was 28 years (range 4 to 40$) .14 \%$ (6/43) of patients had pre-existing hypertension. It is unclear how many had a prior intracranial haemorrhage. 35\% (15/43) had pure ICH, 9\% (4/43) had ICH with subarachnoid haemorrhage, 21\% (9/43) had ICH with intraventricular haemorrhage, $7 \%(3 / 43)$ had ICH with subdural haemorrhage, 23\% (10/43) had ICH with subarachnoid and intraventricular haemorrhage, and $5 \%(2 / 43)$ had ICH with subarachnoid, intraventricular, and subdural haemorrhage. ICH was lobar in $27(63 \%)$ cases, deep in $5(12 \%)$ cases, infratentorial in $9(21 \%)$ cases, and mixed in $2(4 \%)$ cases. Mean ICH size at presentation was not documented

Retrospective case series. All participants underwent both the index and reference standard

The index test was CTA performed using a 16- or 64-slice GE Healthcare helical CT scanner. The skull base to the vertex was scanned using a pitch of $0.7,3 \mathrm{~mm}$ slice thickness, and a field of view of $18 \mathrm{~cm}$. Isovue 370 non-ionic contrast material (90 to $120 \mathrm{~mL}$ ) was administered by power injector at 2 to $3 \mathrm{~mL} / \mathrm{s}$ with either a fixed 25 -second delay between onset of contrast material injection and start of scanning (or a delay of 40 seconds if the participant had atrial fibrillation) or by SmartPrep automatic contrastbolus triggering technique. A positive result was defined as any underlying vascular

Computed tomography angiography or magnetic resonance angiography for detection of intracranial vascular malformations in patients 33 with intracerebral haemorrhage (Review)

Copyright $\Subset 2014$ The Cochrane Collaboration. Published by John Wiley \& Sons, Ltd. 
Romero 2009 (Continued)

abnormality accounting for the haemorrhage

Follow-up

The authors did not state whether there were any study withdrawals. The authors did not report whether there were any instances of uninterpretable images. The authors did not report whether any participants suffered an adverse event

Level of expertise of those interpreting the A neuroradiologist evaluated the CTA source and maximum intensity projection images index test

blinded to the participant's clinical information

Notes

The resulting $1.25 \mathrm{~mm}$ thick axial CTA source images were digitally archived and standard maximum intensity projection images of the major intracranial vessels were created by the 3-D laboratory

Table of Methodological Quality

\begin{tabular}{|c|c|c|}
\hline Item & Authors' judgement & Description \\
\hline Representative spectrum? & No & $\begin{array}{l}\text { Patients older than } 40 \text { were excluded from } \\
\text { the study }\end{array}$ \\
\hline $\begin{array}{l}\text { Acceptable reference standard? } \\
\text { All tests }\end{array}$ & Yes & $\begin{array}{l}\text { IADSA was performed by an expert opera- } \\
\text { tor and was described well enough to repli- } \\
\text { cate through appropriate references to the } \\
\text { literature }\end{array}$ \\
\hline $\begin{array}{l}\text { Acceptable delay between tests? } \\
\text { All tests }\end{array}$ & Yes & $\begin{array}{l}\text { The time between IADSA and CTA was } \leq \\
48 \text { hours }\end{array}$ \\
\hline $\begin{array}{l}\text { Partial verification avoided? } \\
\text { All tests }\end{array}$ & No & $\begin{array}{l}\text { This is a retrospective study and, in routine } \\
\text { practice, the CTA result would be expected } \\
\text { to influence the decision to proceed to ei- } \\
\text { ther to IADSA or straight to surgery }\end{array}$ \\
\hline $\begin{array}{l}\text { Differential verification avoided? } \\
\text { All tests }\end{array}$ & Yes & $\begin{array}{l}\text { IADSA, surgical findings, and pathology } \\
\text { were used as reference standards. However, } \\
\text { data exclusive to IADSA as a reference stan- } \\
\text { dard were obtained from the authors }\end{array}$ \\
\hline $\begin{array}{l}\text { Incorporation avoided? } \\
\text { All tests }\end{array}$ & Yes & $\begin{array}{l}\text { CTA did not form a part of the reference } \\
\text { standard }\end{array}$ \\
\hline $\begin{array}{l}\text { Reference standard results blinded? } \\
\text { All tests }\end{array}$ & No & $\begin{array}{l}\text { Those interpreting the IADSA knew the } \\
\text { results of the CTA scan }\end{array}$ \\
\hline $\begin{array}{l}\text { Index test results blinded? } \\
\text { All tests }\end{array}$ & Yes & $\begin{array}{l}\text { Those interpreting the CTA were blinded } \\
\text { to the IADSA result }\end{array}$ \\
\hline
\end{tabular}


Romero 2009 (Continued)

\begin{tabular}{l|ll}
\hline $\begin{array}{l}\text { Relevant clinical information? } \\
\text { All tests }\end{array}$ & No & $\begin{array}{l}\text { Those interpreting the CTA images were } \\
\text { blinded to all relevant clinical information } \\
\text { including clinical condition and image re- } \\
\text { ports }\end{array}$ \\
\hline $\begin{array}{l}\text { Uninterpretable results reported? } \\
\text { All tests }\end{array}$ & Unclear & No comment was made about uninter- \\
\hline $\begin{array}{l}\text { Withdrawals explained? } \\
\text { All tests }\end{array}$ & Yes & pretable scans \\
\hline $\begin{array}{l}\text { Index test interpreted by an expert? } \\
\text { All tests }\end{array}$ & Yes & $\begin{array}{l}\text { All participants could be accounted for in } \\
\text { the paper }\end{array}$ \\
\hline
\end{tabular}

\section{Wong 2010}

Clinical features and settings

This study enrolled patients from a tertiary care referral centre in Hong Kong, China, who were admitted for cerebral angiography during the subacute phase (6 to 18 weeks) following spontaneous ICH. All patients had ICH confirmed by CT scan performed within 24 hours of clinical onset. Only patients whose ICH was detected with both MRI and IADSA during the subacute phase were included in the study. Patients with predominant subarachnoid haemorrhage were excluded as were those over 45 years with pre-existing hypertension and thalamic, putaminal, or posterior fossa haemorrhage

Participants

It is unclear how many patients were screened for inclusion. 169 patients were eligible and all were enrolled. 18 participants had to withdraw from the study (10 were too unwell to undergo MRI and 8 had an MRI from another institution). Females comprised $38 \%$ (57/151) of the total population. The mean age was 42 years (SD 15). Over onethird of patients had pre-existing hypertension $(52 / 151$; 34\%). It is unclear how many had a prior intracranial haemorrhage. ICH was lobar in $80(53 \%)$ cases, deep in 49 $(32 \%)$ cases, and infratentorial in $22(15 \%)$ cases. Mean ICH size at presentation was not documented

Study design

Retrospective case series. All participants underwent both the index and reference standard

Target condition and reference standard(s) The reference standard was a Phillips V3000 biplanar DSA unit with catheterisation of the relevant cerebral vessels. Technical specifications were not documented. Relevant cervical vessels were catheterised depending on the location of the ICH. Standard views were obtained by hand injection of Omnipaque $3006 \mathrm{~mL}$ to $9 \mathrm{~mL}$ and $3 \mathrm{D}$ angiography was performed for participants with vascular lesions. A positive result was a vascular abnormality accounting for the haemorrhage

Index and comparator tests

The index test was MRA performed using a 1.5 Tesla whole body scanner with a standard head coil (Magnetom Sonata, Siemens Medical Systems or Intera-NT, Phillips Medical Systems). MRA without contrast was performed using 3-dimensional time of flight with a slice thickness of $0.7 \mathrm{~mm}$. An arteriovenous malformation was suspected if the MRA source images showed a conglomerate of parenchymal curvilinear structures. A dural

Computed tomography angiography or magnetic resonance angiography for detection of intracranial vascular malformations in patients 35 with intracerebral haemorrhage (Review)

Copyright $\odot 2014$ The Cochrane Collaboration. Published by John Wiley \& Sons, Ltd. 
arteriovenous fistula was suspected if MRA showed multiple curvilinear structures over the surface of the brain without parenchymal evidence of a nidus

Follow-up

Study withdrawals were explained by the authors. The authors did not report whether there were any instances of uninterpretable images. The authors did not report whether any participants suffered an adverse event

Level of expertise of those interpreting the All MRA images were reviewed by 2 neuroradiologists index test

Notes

Standard maximum intensity projection images of the major intracranial vessels were created following MRA

Table of Methodological Quality

\begin{tabular}{|c|c|c|}
\hline Item & Authors' judgement & Description \\
\hline Representative spectrum? & No & $\begin{array}{l}\text { Patients were admitted for IADSA dur- } \\
\text { ing the subacute period following ICH } \\
\text { onset. Patients over the age of } 45 \text { years } \\
\text { with pre-existing hypertension and thala- } \\
\text { mic, putaminal, or posterior fossa haemor- } \\
\text { rhages were excluded }\end{array}$ \\
\hline $\begin{array}{l}\text { Acceptable reference standard? } \\
\text { All tests }\end{array}$ & Yes & $\begin{array}{l}\text { IADSA was performed by an expert oper- } \\
\text { ator }\end{array}$ \\
\hline $\begin{array}{l}\text { Acceptable delay between tests? } \\
\text { All tests }\end{array}$ & Yes & Time from onset to each test was recorded \\
\hline $\begin{array}{l}\text { Partial verification avoided? } \\
\text { All tests }\end{array}$ & No & $\begin{array}{l}\text { This is a retrospective study and, in routine } \\
\text { practice, the MRA result would influence } \\
\text { the decision to proceed to IADSA }\end{array}$ \\
\hline $\begin{array}{l}\text { Differential verification avoided? } \\
\text { All tests }\end{array}$ & Yes & IADSA was the only reference standard \\
\hline $\begin{array}{l}\text { Incorporation avoided? } \\
\text { All tests }\end{array}$ & Yes & $\begin{array}{l}\text { MRA did not form a part of the reference } \\
\text { standard }\end{array}$ \\
\hline $\begin{array}{l}\text { Reference standard results blinded? } \\
\text { All tests }\end{array}$ & Yes & $\begin{array}{l}\text { Those interpreting the IADSA were } \\
\text { blinded to the MRA result }\end{array}$ \\
\hline $\begin{array}{l}\text { Index test results blinded? } \\
\text { All tests }\end{array}$ & Yes & $\begin{array}{l}\text { Those interpreting the MRA were blinded } \\
\text { to the IADSA result }\end{array}$ \\
\hline $\begin{array}{l}\text { Relevant clinical information? } \\
\text { All tests }\end{array}$ & Unclear & $\begin{array}{l}\text { It is unclear whether those interpreting the } \\
\text { MRA and IADSA images had access to all } \\
\text { relevant clinical information apart from the }\end{array}$ \\
\hline
\end{tabular}


results of the competing scan

\begin{tabular}{l|ll}
\hline $\begin{array}{l}\text { Uninterpretable results reported? } \\
\text { All tests }\end{array}$ & Unclear & $\begin{array}{l}\text { No comment was made about uninter- } \\
\text { pretable scans }\end{array}$ \\
\hline $\begin{array}{l}\text { Withdrawals explained? } \\
\text { All tests }\end{array}$ & Yes & Participant withdrawals were explained \\
\hline $\begin{array}{l}\text { Index test interpreted by an expert? } \\
\text { All tests }\end{array}$ & Yes & $\begin{array}{l}\text { All MRA images were reviewed by 2 neu- } \\
\text { roradiologists }\end{array}$ \\
\hline
\end{tabular}

\section{Wong 2011}

Clinical features and settings

Participants
The study enrolled consecutive patients from a tertiary care referral centre in Hong Kong, China, who presented with spontaneous, non-hypertensive and/or lobar intracerebral haemorrhage within 96 hours of the clinical ictus. Patients older than 45 years with preexisting hypertension and thalamic, putaminal, or posterior fossa haemorrhage, those older than 70 years, those with known renal impairment or an allergy to intravenous contrast, and those with an emergency craniotomy before IADSA were excluded

966 patients were screened, 135 were eligible, and 109 consented to the study. Females comprised 33\% (36/109) of the total population. The mean age was 48 (SD 15). No participants were considered to have had premorbid hypertension. It is unclear how many had a prior intracranial haemorrhage. 12 participants (10\%) had pure ICH, 18 (17\%) had ICH with subdural haemorrhage, 42 (39\%) had ICH with subarachnoid haemorrhage, and 37 (34\%) had ICH with intraventricular haemorrhage. ICH was lobar in $80(73 \%)$ cases, deep in $20(19 \%)$ cases, and infratentorial in $9(8 \%)$ cases. Mean ICH size at presentation was $10 \mathrm{~mL}$ (SD 22)

Study design Prospective case series of consecutive patients presenting with spontaneous ICH

Target condition and reference standard(s) The reference standard was a Phillips V3000 DSA unit with catheterisation of the relevant cerebral vessels. Technical specifications were not documented. Relevant cervical vessels were catheterised depending on the location of the ICH. Standard views were obtained by hand injection of Omnipaque $3006 \mathrm{~mL}$ to $9 \mathrm{~mL}$ and 3D angiography was performed for participants with vascular lesions. A positive result was defined as any underlying vascular aetiology for the ICH

Index and comparator tests

The index test was CTA performed using a 64-slice GE Healthcare helical CT scan with the assistance of SmartPrep bolus tracking software. Arteriography was performed in helical mode $120 \mathrm{kV}, 220 \mathrm{mAs}$ with no tilting. Axial images were reconstructed at 0 . $625 \mathrm{~mm}$ intervals and stored as source images for further analysis with 3-dimensional reconstruction. A positive result was defined as any underlying vascular aetiology for the $\mathrm{ICH}$

Follow-up

The authors did not state whether there were any study withdrawals. The authors did not report whether there were any instances of uninterpretable images. The authors did not report whether any participants suffered an adverse event 


\section{Wong 2011 (Continued)}

Level of expertise of those interpreting the 2 neuroradiologists blind to both the clinical data and the catheter angiography findings index test interpreted the CTA scans

Notes

Standard multiplanar reformatting and maximum intensity projection images of the major intracranial vessels were created following CTA. We were able to reclassify cases of brain tumours and venous sinus thrombosis as 'negatives' using the published data

Table of Methodological Quality

\begin{tabular}{|c|c|c|}
\hline Item & Authors' judgement & Description \\
\hline Representative spectrum? & No & $\begin{array}{l}\text { All patients } 70 \text { years of age or older and } \\
\text { those between } 45 \text { to } 69 \text { years of age with } \\
\text { pre-existing hypertension and thalamic, } \\
\text { putaminal, or posterior fossa haemorrhages } \\
\text { were excluded }\end{array}$ \\
\hline $\begin{array}{l}\text { Acceptable reference standard? } \\
\text { All tests }\end{array}$ & Yes & $\begin{array}{l}\text { IADSA was performed by an expert oper- } \\
\text { ator }\end{array}$ \\
\hline $\begin{array}{l}\text { Acceptable delay between tests? } \\
\text { All tests }\end{array}$ & Yes & Time from onset to each test was recorded \\
\hline $\begin{array}{l}\text { Partial verification avoided? } \\
\text { All tests }\end{array}$ & Yes & $\begin{array}{l}\text { The CTA result did not determine who un- } \\
\text { derwent IADSA }\end{array}$ \\
\hline $\begin{array}{l}\text { Differential verification avoided? } \\
\text { All tests }\end{array}$ & Yes & IADSA was the only reference standard \\
\hline $\begin{array}{l}\text { Incorporation avoided? } \\
\text { All tests }\end{array}$ & Yes & $\begin{array}{l}\text { CTA did not form a part of the reference } \\
\text { standard }\end{array}$ \\
\hline $\begin{array}{l}\text { Reference standard results blinded? } \\
\text { All tests }\end{array}$ & Yes & $\begin{array}{l}\text { Those interpreting the IADSA were } \\
\text { blinded to the CTA result }\end{array}$ \\
\hline $\begin{array}{l}\text { Index test results blinded? } \\
\text { All tests }\end{array}$ & Yes & $\begin{array}{l}\text { Those interpreting the CTA were blinded } \\
\text { to the IADSA result }\end{array}$ \\
\hline $\begin{array}{l}\text { Relevant clinical information? } \\
\text { All tests }\end{array}$ & No & $\begin{array}{l}\text { Neuroradiologists interpreting the CTA } \\
\text { and IADSA scans were blinded to clinical } \\
\text { data }\end{array}$ \\
\hline $\begin{array}{l}\text { Uninterpretable results reported? } \\
\text { All tests }\end{array}$ & Unclear & $\begin{array}{l}\text { No comment was made about uninter- } \\
\text { pretable scans }\end{array}$ \\
\hline $\begin{array}{l}\text { Withdrawals explained? } \\
\text { All tests }\end{array}$ & Yes & $\begin{array}{l}\text { All participants could be accounted for in } \\
\text { the paper }\end{array}$ \\
\hline
\end{tabular}




\begin{tabular}{|c|c|c|}
\hline $\begin{array}{l}\text { Index test interpreted by an expert? } \\
\text { All tests }\end{array}$ & Yes & $\begin{array}{l}\text { All CTA scans were interpreted separately } \\
\text { by } 2 \text { neuroradiologists }\end{array}$ \\
\hline
\end{tabular}

\section{Yeung 2009}

\begin{tabular}{ll} 
Clinical features and settings & $\begin{array}{l}\text { Patients admitted to tertiary care centre in Toronto, Canada, with nontraumatic, primar- } \\
\text { ily non-subarachnoid haemorrhage. Patients had to have undergone CTA and IADSA } \\
\text { prior to any surgical intervention }\end{array}$ \\
\hline Participants & $\begin{array}{l}286 \text { patients were screened and } 55 \text { met the eligibility criteria and were enrolled. The } \\
\text { study population was } 58 \%(32 / 55) \text { male and the median age was } 49 \text { years (range } 16 \text { to }\end{array}$ \\
$\begin{array}{l}71) \text { for males and } 50 \text { years (range } 30 \text { to } 79) \text { for females. No details were provided about } \\
\text { co-morbidities. Lobar haemorrhages were present in } 31 \text { participants, deep haemorrhages } \\
\text { in } 9 \text {, and infratentorial haemorrhages in } 7 \text {. Pure intraventricular haemorrhage occurred } \\
\text { in } 5 \text { participants and pure subdural haemorrhage occurred in } 3 \text { participants }\end{array}$
\end{tabular}

Study design

Retrospective case series. All participants underwent both the index test and reference standard

Target condition and reference standard(s) IADSA was performed using a Phillips uniplane neuroangiographic unit. Technical specifications were not provided. Selective injections were performed according to the side of the haematoma and the presence of a CTA detected abnormality. Both external and internal carotid vessels were imaged in cases where no cause was seen on CTA. A positive result was the presence of a 'secondary cause' of haemorrhage

Index and comparator tests

The index test was CTA. All scans were performed using a GE Medical Systems LightSpeed Plus 4-slice CT or VCT 64-slice helical scanner. Each covered at least C2 to the vertex. The parameters used included 1.25 or $0.625 \mathrm{~mm}$ slice thickness (depending on the scanner). The matrix, pitch, and field of view were not specified. A total of $100 \mathrm{~mL}$ to $125 \mathrm{~mL}$ Omnipaque 300 or Visipaque 320 were injected at a rate of $4.0 \mathrm{~mL} / \mathrm{s}$ to 4.5 $\mathrm{mL} / \mathrm{s}$ with either a 17-second delay or the use of Smart Prep at the pulmonary artery. A positive result was the presence of a 'secondary cause' of haemorrhage

Follow-up

The authors did not state whether there were any study withdrawals. The authors did not report whether there were any instances of uninterpretable images. The authors did not report whether any participants suffered an adverse event

Level of expertise of those interpreting the index test

3 staff neuroradiologists blinded to participant information and other imaging studies independently reviewed all CTA studies

Notes

Coronal and sagittal multiplanar reformatting images were recreated at $7 \mathrm{~mm}$ thickness spaced by $3 \mathrm{~mm}$. Bilateral 5-degree rotational multiplanar reformatting images were created at the carotid terminus. The $3 \mathrm{D}$ rendered images were created on a GE Advantage Workstation

Table of Methodological Quality

Computed tomography angiography or magnetic resonance angiography for detection of intracranial vascular malformations in patients with intracerebral haemorrhage (Review)

Copyright $(2014$ The Cochrane Collaboration. Published by John Wiley \& Sons, Ltd. 
Yeung 2009 (Continued)

\begin{tabular}{|c|c|c|}
\hline Item & Authors' judgement & Description \\
\hline Representative spectrum? & Yes & $\begin{array}{l}\text { Participants all had acute intraparenchymal } \\
\text { ICH (with or without extension into other } \\
\text { intracranial spaces), were well enough to } \\
\text { undergo both tests, had no contraindica- } \\
\text { tions to either CTA or IADSA, and were } \\
\text { recruited with the express purpose of deter- } \\
\text { mining the diagnostic accuracy of CTA }\end{array}$ \\
\hline $\begin{array}{l}\text { Acceptable reference standard? } \\
\text { All tests }\end{array}$ & Yes & $\begin{array}{l}\text { The reference standard was IADSA and was } \\
\text { described in sufficient detail to replicate }\end{array}$ \\
\hline $\begin{array}{l}\text { Acceptable delay between tests? } \\
\text { All tests }\end{array}$ & Yes & The delay between tests was reported \\
\hline $\begin{array}{l}\text { Partial verification avoided? } \\
\text { All tests }\end{array}$ & No & $\begin{array}{l}\text { The CTA result determined who under- } \\
\text { went IADSA }\end{array}$ \\
\hline $\begin{array}{l}\text { Differential verification avoided? } \\
\text { All tests }\end{array}$ & Yes & IADSA was the only reference standard \\
\hline $\begin{array}{l}\text { Incorporation avoided? } \\
\text { All tests }\end{array}$ & Yes & $\begin{array}{l}\text { CTA did not form a part of the reference } \\
\text { standard }\end{array}$ \\
\hline $\begin{array}{l}\text { Reference standard results blinded? } \\
\text { All tests }\end{array}$ & Unclear & $\begin{array}{l}2 \text { neuroradiologists reviewed the IADSAs } \\
\text { at least } 1 \text { month after the CTA to reduce } \\
\text { recall bias }\end{array}$ \\
\hline $\begin{array}{l}\text { Index test results blinded? } \\
\text { All tests }\end{array}$ & Yes & $\begin{array}{l}\text { The CTA images were interpreted blinded } \\
\text { to the IADSA result }\end{array}$ \\
\hline $\begin{array}{l}\text { Relevant clinical information? } \\
\text { All tests }\end{array}$ & No & $\begin{array}{l}\text { Those interpreting the CTA and IADSA } \\
\text { images were blinded to all participant in- } \\
\text { formation }\end{array}$ \\
\hline $\begin{array}{l}\text { Uninterpretable results reported? } \\
\text { All tests }\end{array}$ & Unclear & $\begin{array}{l}\text { The authors did not state whether uninter- } \\
\text { pretable images were encountered }\end{array}$ \\
\hline $\begin{array}{l}\text { Withdrawals explained? } \\
\text { All tests }\end{array}$ & Yes & $\begin{array}{l}\text { All participants could be accounted for in } \\
\text { the paper }\end{array}$ \\
\hline $\begin{array}{l}\text { Index test interpreted by an expert? } \\
\text { All tests }\end{array}$ & Yes & $\begin{array}{l}3 \text { staff neuroradiologists independently re- } \\
\text { viewed all CTA studies }\end{array}$ \\
\hline
\end{tabular}


Clinical features and settings

Study design

Target condition and reference standard(s)

Index and comparator tests

Follow-up

Level of expertise of those interpreting the All CTA images were independently evaluated by 2 neuroradiologists

index test

Notes

Multi-detector CTA was reconstructed into transverse sections with a section width of 0.5 $\mathrm{mm}$ from the source images using sagittal and coronal multiplanar reformations, volumerendered technique, and volume-rendered technique after automatic segmentation of a pre-contrast scan data set. We were able to reclassify cases of moya-moya as 'negatives' after receiving data from the authors

Table of Methodological Quality

\begin{tabular}{lll}
\hline Item & Authors' judgement & Description \\
\hline Representative spectrum? & Yes & $\begin{array}{l}\text { Participants were all prospectively identi- } \\
\text { fied, consecutive cases with acute intra- } \\
\text { parenchymal ICH (with or without exten- } \\
\text { sion into other intracranial spaces) who }\end{array}$
\end{tabular}

Computed tomography angiography or magnetic resonance angiography for detection of intracranial vascular malformations in patients with intracerebral haemorrhage (Review)

Copyright $\odot 2014$ The Cochrane Collaboration. Published by John Wiley \& Sons, Ltd.

Multi-detector CTA was obtained using a 16-detector row CT scanner (Phillips MX8000 Infinite Detector Technology) The parameters used included $1 \mathrm{~mm}$ slice thickness, a 512 x 512 matrix, a pitch of 0.35 , and a 20 to $22 \mathrm{~cm}$ field of view. Participants were scanned valuture. A total of 100 to 120 mL of iohexol (Omnipaque 300 ; GE Healthcare) was administered intravenously using a bolus-tracking technique. A positive result was an underlying vascular abnormality accounting for the haemorrhage

Study withdrawals were explained. There was no mention of uninterpretable scans. There was no statement regarding adverse effects

105 patients were screened and 88 were eligible but 10 were not enrolled because they were therefore enrolled. The mean age was 48 years (SD 14). Over half (44/78; 56\%) were male. No details were provided about co-morbidities. All 78 had lobar ICH and bilateral vertebral artery injections were performed for each case. Anteroposterior, lateral, oblique, and additional views of each vessel, if necessary, were obtained using $6 \mathrm{~mL}$ to 9 $\mathrm{mL}$ of iodixanol (Visipaque 320, GE Healthcare) injected at a rate of $4 \mathrm{~mL} / \mathrm{s}$ to $6 \mathrm{~mL} / \mathrm{s}$. A positive result was an underlying vascular abnormality accounting for the haemorrhage

The study included patients referred to a tertiary care referral centre in Seoul, South
Korea, for investigation of spontaneous ICH. Patients with predominant subarachnoid haemorrhage, known pre-existing vascular abnormalities, or those with haemorrhage into a tumour were excluded

intraventricular compartments

Prospective case series. All participants underwent both the index and reference standard from the foramen magnum through the top of the skull including the entire cerebral 


\begin{tabular}{|c|c|c|}
\hline & & $\begin{array}{l}\text { were well enough to undergo both CTA } \\
\text { and IADSA, had no contraindications to } \\
\text { CTA or IADSA, and were recruited with } \\
\text { the express purpose of determining the di- } \\
\text { agnostic accuracy of CTA }\end{array}$ \\
\hline $\begin{array}{l}\text { Acceptable reference standard? } \\
\text { All tests }\end{array}$ & Yes & $\begin{array}{l}\text { The reference standard was IADSA for all } \\
\text { participants }\end{array}$ \\
\hline $\begin{array}{l}\text { Acceptable delay between tests? } \\
\text { All tests }\end{array}$ & Yes & The delay between tests was reported \\
\hline $\begin{array}{l}\text { Partial verification avoided? } \\
\text { All tests }\end{array}$ & Yes & $\begin{array}{l}\text { CTA results did not influence who under- } \\
\text { went IADSA }\end{array}$ \\
\hline $\begin{array}{l}\text { Differential verification avoided? } \\
\text { All tests }\end{array}$ & Yes & $\begin{array}{l}\text { All participants underwent IADSA as the } \\
\text { reference standard }\end{array}$ \\
\hline $\begin{array}{l}\text { Incorporation avoided? } \\
\text { All tests }\end{array}$ & Yes & $\begin{array}{l}\text { CTA did not form a part of the reference } \\
\text { standard }\end{array}$ \\
\hline $\begin{array}{l}\text { Reference standard results blinded? } \\
\text { All tests }\end{array}$ & Yes & $\begin{array}{l}\text { IADSA was interpreted independent of } \\
\text { CTA }\end{array}$ \\
\hline $\begin{array}{l}\text { Index test results blinded? } \\
\text { All tests }\end{array}$ & Yes & $\begin{array}{l}\text { CTA was interpreted independent of the } \\
\text { IADSA }\end{array}$ \\
\hline $\begin{array}{l}\text { Relevant clinical information? } \\
\text { All tests }\end{array}$ & Unclear & $\begin{array}{l}\text { There was no statement about whether } \\
\text { those interpreting the CTA and IADSA } \\
\text { were provided with all relevant clinical in- } \\
\text { formation apart from the results of the } \\
\text { competing test }\end{array}$ \\
\hline $\begin{array}{l}\text { Uninterpretable results reported? } \\
\text { All tests }\end{array}$ & Unclear & $\begin{array}{l}\text { There was no statement about whether un- } \\
\text { interpretable test results were encountered }\end{array}$ \\
\hline $\begin{array}{l}\text { Withdrawals explained? } \\
\text { All tests }\end{array}$ & Yes & Study withdrawals were explained \\
\hline $\begin{array}{l}\text { Index test interpreted by an expert? } \\
\text { All tests }\end{array}$ & Yes & $\begin{array}{l}\text { All CTA images were independently evalu- } \\
\text { ated by } 2 \text { neuroradiologists }\end{array}$ \\
\hline
\end{tabular}


Clinical features and settings

Study design

Target condition and reference standard(s)

Index and comparator tests

Level of expertise of those interpreting the index test
The study included patients referred to a tertiary care referral centre at Xi' an Jiaotong University, China, for investigation of subacute ICH defined as assessment within 1 week of symptom onset. Diagnosis was made according to the 4th National Vascular Diagnostic Criteria. Patients with blood disorders, space occupying lesions, extracranial pathology, and meningitis were excluded

183 participants were enrolled. The mean age was 43.7 years (SD 14.9). Overall age ranged from 18 to 81 . Slightly over half $(97 / 183 ; 53 \%)$ were male. No details were provided about co-morbidities apart from pre-existing hypertension (present in 52/183; $28 \%)$. Anatomical haemorrhage location was lobar in $106(58 \%)$, deep in $55(30 \%)$, and infratentorial in $22(12 \%)$

It was unclear whether the case series was prospective or retrospective. All participants underwent both the index and reference standard

IADSA was performed using a Phillips system. Unit specifications were not provided. Bilateral selective internal carotid and vertebral artery injections were performed for each case. Anteroposterior, lateral, and oblique views of each vessel were obtained. A positive test result was not formally defined

The MRA unit was not described. 3-dimensional time of flight imaging was acquired with a slice thickness of $2.0 \mathrm{~mm}$ and a matrix size of $512 \times 256$. A positive test result was not formally defined

Study withdrawals were explained. There was no mention of uninterpretable scans. There was no statement regarding adverse effects

MRA images were interpreted by either a radiologist or a neurosurgeon. There is no statement as to whether the reviewers were blinded to the results of IADSA

\section{Notes}

$-$

Table of Methodological Quality

\begin{tabular}{l|ll}
\hline Item & Authors' judgement & Description \\
\hline $\begin{array}{l}\text { Representative spectrum? } \\
\text { Yes }\end{array}$ & Yes & $\begin{array}{l}\text { Patients with CT-confirmed subacute (as- } \\
\text { sessed within 1 week of ictus) intracerebral } \\
\text { haemorrhage were included }\end{array}$ \\
\hline $\begin{array}{l}\text { Acceptable reference standard? } \\
\text { All tests }\end{array}$ & No & The reference standard was IADSA for all \\
\hline $\begin{array}{l}\text { Acceptable delay between tests? } \\
\text { All tests }\end{array}$ & No & The authors did not indicate the delay be- \\
\hline $\begin{array}{l}\text { Partial verification avoided? } \\
\text { All tests }\end{array}$ & & tween MRA and IADSA \\
\hline
\end{tabular}


Zhou 2012 (Continued)

\begin{tabular}{|c|c|c|}
\hline $\begin{array}{l}\text { Differential verification avoided? } \\
\text { All tests }\end{array}$ & Yes & $\begin{array}{l}\text { All participants underwent IADSA as the } \\
\text { reference standard }\end{array}$ \\
\hline $\begin{array}{l}\text { Incorporation avoided? } \\
\text { All tests }\end{array}$ & Yes & $\begin{array}{l}\text { MRA did not form a part of the reference } \\
\text { standard }\end{array}$ \\
\hline $\begin{array}{l}\text { Reference standard results blinded? } \\
\text { All tests }\end{array}$ & Unclear & $\begin{array}{l}\text { The study does not state whether IADSA } \\
\text { was interpreted blinded to the MRA results }\end{array}$ \\
\hline $\begin{array}{l}\text { Index test results blinded? } \\
\text { All tests }\end{array}$ & Unclear & $\begin{array}{l}\text { The study does not state whether MRA was } \\
\text { interpreted blinded to the IADSA results }\end{array}$ \\
\hline $\begin{array}{l}\text { Relevant clinical information? } \\
\text { All tests }\end{array}$ & Unclear & $\begin{array}{l}\text { There was no statement about whether } \\
\text { those interpreting the MRA and IADSA } \\
\text { were provided with all relevant clinical in- } \\
\text { formation apart from the results of the } \\
\text { competing test }\end{array}$ \\
\hline $\begin{array}{l}\text { Uninterpretable results reported? } \\
\text { All tests }\end{array}$ & Unclear & $\begin{array}{l}\text { There was no statement about whether un- } \\
\text { interpretable test results were encountered }\end{array}$ \\
\hline $\begin{array}{l}\text { Withdrawals explained? } \\
\text { All tests }\end{array}$ & Yes & $\begin{array}{l}\text { All participants could be accounted for in } \\
\text { the paper }\end{array}$ \\
\hline $\begin{array}{l}\text { Index test interpreted by an expert? } \\
\text { All tests }\end{array}$ & No & $\begin{array}{l}\text { Not all of the results were reviewed by a } \\
\text { neuroradiologist (some were only reviewed } \\
\text { by neurosurgeons) }\end{array}$ \\
\hline
\end{tabular}

CT: computed tomography

CTA: computed tomography angiography

IADSA: intra-arterial digital subtraction angiography

ICH: intracerebral haemorrhage

MIP: maximum intensity projection

MRA: magnetic resonance angiography

MRI: magnetic resonance imaging

SD: standard deviation

Characteristics of excluded studies [ordered by study ID] 


\begin{tabular}{|c|c|}
\hline Study & Reason for exclusion \\
\hline Awad 1992 & Unable to obtain data exclusive to IADSA \\
\hline Bekelis 2012 & Unable to obtain data exclusive to IADSA \\
\hline Bowen 2007 & Review article \\
\hline Campeau 2012 & Review article \\
\hline Chandra 2012 & Review article \\
\hline Dammert 2004 & Study population was SAH or 'atypical' ICH \\
\hline Elhammady 2008 & IADSA was not the reference standard \\
\hline Evans 2005 & Overall study population of $<20$ participants \\
\hline Fasulakis 2003 & Study was performed on patients with known AVMs (the study population was therefore not ICH) \\
\hline Griffiths 2006 & The study population consisted of subarachnoid and intraventricular haemorrhage \\
\hline Gross 2012 & The study population was not ICH \\
\hline Hünerbein 2003 & Unable to obtain data exclusive to IADSA \\
\hline Kadkhodayan 2012 & No CTA or MRA data \\
\hline Kamel 2013 & No comparison between MRA and IADSA \\
\hline Khosravani 2013 & No comparison between MRA and IADSA \\
\hline Kidwell 2010 & Review article \\
\hline Lee 2007 & Unable to obtain data exclusive to IADSA \\
\hline Leung 2012 & Review article \\
\hline Li 2013 & IADSA was not the reference standard \\
\hline Pott 1992 & Index test was not CTA or MRA \\
\hline Sasiadek 2000 & Insufficient information \\
\hline Sasiadek 2002 & Insufficient information \\
\hline Sha 2008 & Unable to obtain data exclusive to IADSA \\
\hline Truwit 2007 & Review article \\
\hline
\end{tabular}


(Continued)

Wijman 2012

IADSA was not the reference standard

Zheng 2012

No comparison with IADSA

AVM: arteriovenous malformation

CTA: computed tomography angiography

IADSA: intra-arterial digital subtraction angiography

ICH: intracerebral haemorrhage

MRA: magnetic resonance imaging

SAH: subarachnoid haemorrhage 


\section{A T A}

Presented below are all the data for all of the tests entered into the review.

Tests. Data tables by test

\begin{tabular}{lcr} 
Test & $\begin{array}{c}\text { No. of } \\
\text { studies }\end{array}$ & $\begin{array}{c}\text { No. of } \\
\text { participants }\end{array}$ \\
\hline 1 CTA & 8 & 526 \\
2 MRA & 3 & 401 \\
\hline
\end{tabular}

Test I. CTA.

Review: Computed tomography angiography or magnetic resonance angiography for detection of intracranial vascular malformations in patients with intracerebral haemorrhage

Test: I CTA

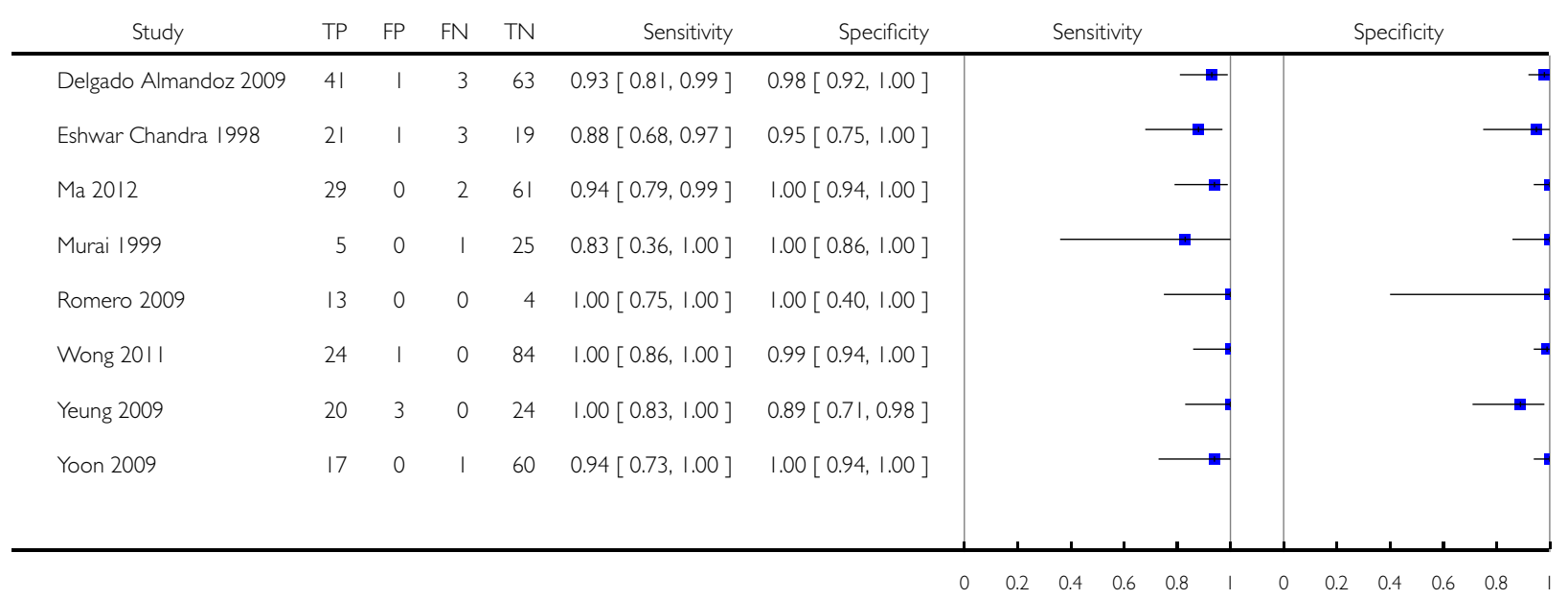

Computed tomography angiography or magnetic resonance angiography for detection of intracranial vascular malformations in patients 
Test 2. MRA.

Review: Computed tomography angiography or magnetic resonance angiography for detection of intracranial vascular malformations in patients with intracerebral haemorrhage

Test: 2 MRA

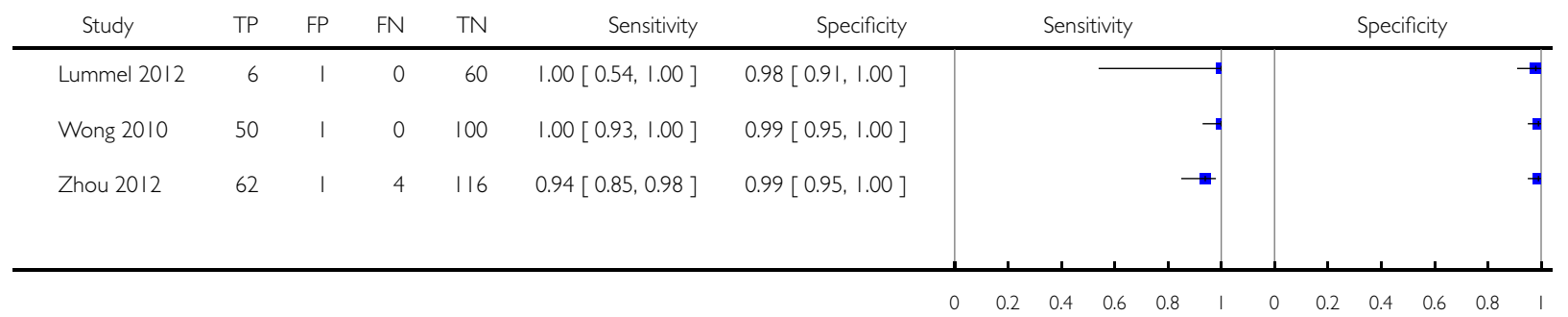

\section{A P P E N D I C E S}

\section{Appendix I. MEDLINE search strategy}

1. exp basal ganglia hemorrhage/ or intracranial hemorrhages/ or cerebral hemorrhage/ or intracranial hemorrhage, hypertensive/ or cerebrovascular disorders/

2. ( (brain \$ or cerebr\$ or cerebell\$ or intracerebral or intracran $\$$ or parenchymal or intraparenchymal or intraventricular or infratentorial or supratentorial or basal gangli $\$$ or putaminal or putamen or posterior fossa or hemispher $\$$ or stroke or apoplex\$) adj10 (h?emorrhage\$ or h?ematoma $\$$ or bleed $\$)$ ).tw.

3. 1 or 2 or ICH.tw.

4. Magnetic Resonance Angiography/

5. angiography/ or cerebral angiography/

6. Magnetic Resonance Imaging/

7. 5 and 6

8. ((magnetic resonance or MR or MRI or NMR) adj5 (angiogra $\$$ or arteriogra $\$)$ ).tw.

9. MRA.tw.

10. exp Tomography, X-Ray Computed/

11. angiography/ or cerebral angiography/

12. 10 and 11

13. ((Compute\$ tomograph\$ or CT or CAT) adj5 (angiogra $\$$ or arteriogra $\$)$ ).tw.

14. CTA.tw.

15.4 or 7 or 8 or 9 or 12 or 13 or 14

16. angiography, digital subtraction/

17. angiography/ and (subtraction technique/ or subtraction.tw.)

18. ((digital subtract $\$$ or catheter or cerebral or brain) adj5 (angiogra $\$$ or arteriogra $\$)$ ).tw.

19. (DSA or IADSA).tw.

20. 16 or 17 or 18 or 19

21.3 and 15 and 20

22. exp *basal ganglia hemorrhage/di, pa, ra or *intracranial hemorrhages/di, pa, ra or *cerebral hemorrhage/di, pa, ra or *intracranial hemorrhage, hypertensive/di, pa, ra or *cerebrovascular disorders/di, pa, ra

Computed tomography angiography or magnetic resonance angiography for detection of intracranial vascular malformations in patients 48 with intracerebral haemorrhage (Review)

Copyright $\odot 2014$ The Cochrane Collaboration. Published by John Wiley \& Sons, Ltd. 


\author{
23. 15 and 22 \\ 24. exp "sensitivity and specificity"/ \\ 25. (sensitiv\$ or specificity).tw. \\ 26. (predictive adj5 value\$).tw. \\ 27. exp diagnostic errors/ \\ 28. ((false adj positive $\$$ ) or (false adj negative $\$)$ ).tw. \\ 29. (observer adj variation\$).tw. \\ 30. (roc adj curve $\$$ ).tw. \\ 31. (likelihood adj3 ratio\$).tw. \\ 32. likelihood function/ \\ 33.24 or 25 or 26 or 27 or 28 or 29 or 30 or 31 or 32 \\ 34.3 and 15 and 33 \\ 35. 21 or 23 or 34 \\ 36. 20 and 22 \\ 37.3 and 20 and 33 \\ 38.35 or 36 or 37
}

\title{
Appendix 2. EMBASE search strategy
}

1. basal ganglion hemorrhage/ or brain hemorrhage/ or brain ventricle hemorrhage/ or cerebellum hemorrhage/ or brain hematoma/ 2. ( (brain \$ or cerebr $\$$ or cerebell\$ or intracerebral or intracran $\$$ or parenchymal or intraparenchymal or intraventricular or infratentorial or supratentorial or basal gangli $\$$ or putaminal or putamen or posterior fossa) adj10 (haemorrhage $\$$ or hemorrhage $\$$ or haematoma $\$$ or hematoma $\$$ or bleed $\$)$ ).tw.

3. 1 or 2 or ICH.tw.

4. magnetic resonance angiography/

5. angiography/ or arteriography/ or exp brain angiography/

6. nuclear magnetic resonance imaging/

7. 5 and 6

8. ((magnetic resonance or MR or MRI or NMR) adj5 (angiogra $\$$ or arteriogra $\$)$ ).tw.

9. MRA.tw.

10. computed tomographic angiography/

11. angiography/or arteriography/or exp brain angiography/

12. computer assisted tomography/or spiral computer assisted tomography/

13. 11 and 12

14. ((compute\$ tomograph\$ or CT or CAT) adj5 (angiogra $\$$ or arteriogra $\$)$ ).tw.

15. CTA.tw.

16. 4 or 7 or 8 or 9 or 10 or 13 or 14 or 15

17. conventional angiography/ or digital subtraction angiography/

18. image subtraction/ or subtraction.tw.

19. angiography/ or arteriography/or exp brain angiography/

20. 18 and 19

21. ((digital subtract $\$$ or catheter or cerebral or brain) adj5 (angiogra $\$$ or arteriogra $\$)$ ).tw.

22. (DSA or IADSA).tw.

23. 17 or 20 or 21 or 22

24. 3 and 16 and 23

25. *basal ganglion hemorrhage/di or *brain hemorrhage/di or *brain ventricle hemorrhage/di or *cerebellum hemorrhage/di or *brain hematoma/di

26. 16 and 25

27. "sensitivity and specificity"/

28. receiver operating characteristic/

29. diagnostic accuracy/

30. exp diagnostic error/

Computed tomography angiography or magnetic resonance angiography for detection of intracranial vascular malformations in patients with intracerebral haemorrhage (Review)

Copyright $\odot 2014$ The Cochrane Collaboration. Published by John Wiley \& Sons, Ltd. 
31. observer variation/

32. "limit of detection"/

33. "diagnostic test accuracy study".sh.

34. (sensitivity or specificity).tw.

35. (predictive adj3 value\$).tw.

36. ((false adj positive\$) or (false adj negative\$)).tw.

37. observer variation $\$$.tw.

38. (roc adj curve $\$$ ).tw.

39. (likelihood adj3 ratio $\$$ ).tw.

40. or/27-39

41.3 and 16 and 40

42. 24 or 26 or 41

43. 23 and 25

44.3 and 23 and 40

45.42 or 43 or 44

\section{Appendix 3. Modified QUADAS methodological items and operational definitions}

\section{Methodological variable}

1. Was the spectrum of patients representative of the patients who will receive the test in practice?

(Spectrum bias)

\section{Operational definition/information required from each study}

Yes: the study population reflects the target population, which we have defined as prospectively identified, consecutive adults $(\geq 16$ years of age) with acute intraparenchymal ICH (with or without extension into other intracranial spaces) who are well enough to undergo the both tests, have no contraindications to either the index test or reference standard, and who are recruited with the express purpose of determining the diagnostic accuracy of the index test

No: the study population does not match these criteria

Unclear: there is insufficient information provided to compare the study population to our ideal target population

2. Is the reference standard likely to correctly classify the target condition?

Yes: IADSA was performed by an expert or experienced operator. We define 'expert' as a neuroradiologist and 'experienced' as a consultant level (or equivalent) radiologist with $\geq 5$ years of clinical experience. In addition, we will require that, at the very minimum, the relevant arterial territories in the vicinity of the haematoma must have been examined

No: IADSA was not performed by an expert or experienced operator or the complete arterial territories surrounding the haematoma were not examined

Unclear: insufficient information is available to evaluate this criterion

3. The delay between the index test and reference standard was documented

(Disease progression bias)
Yes: the mean or median delay ( \pm standard deviation or interquartile range) between the index test and reference standard is explicitly stated

No: the time delay is not reported

Of note, there is no 'appropriate' time frame between tests per se. 
This is partly because we do not know how long the haematoma persists in each case. Residual haematoma could obscure the vascular malformation and therefore studies using longer delays between tests may report varying estimates of accuracy. It is impossible at this point to provide an empirically based 'appropriate' time frame since we do not yet have the data to analyse this question. We aimed to record delay, however, as we wish to establish empirical evidence of what should be an appropriate time frame between tests

4. Did the whole sample or a random selection of the sample, Yes: every patient or a random selection of patients undergoing receive verification using a reference standard?

(Partial verification bias) the index test also received the reference standard

No: the index test played a role in selecting who underwent the reference standard

Unclear: there is insufficient information available to determine if the index test influenced who underwent the reference standard

5. Did patients receive the same reference standard regardless of the index test result?

Yes: all patients undergoing the index test uniformly received the same reference standard

(Differential verification bias)

No: all patients underwent the same index test but underwent different reference standards

Unclear: there is insufficient detail to tell if every participant in the analysis underwent the same reference standard

6. Was the reference standard independent of the index test? (Incorporation bias)
Yes: the index test does not form a part of the reference standard No: the index test is used in conjunction with IADSA as the formal reference standard

Unclear: there is insufficient information to determine whether the index tests formed a part of the reference standard

7. Were the reference standard results interpreted without knowledge of the results of the index test?

(Information bias)

8. Were the index test results interpreted without knowledge of the results of the reference standard?

(Information bias)

9. Were the same clinical data available when test results were interpreted as would be available when the test is used in practice? (Information bias)
Yes: there is an explicit statement that the reference standard was

No: there is an explicit statement that the reference standard was not interpreted blinded to the results of the index test

Unclear: there is no statement specifically describing how the reference standard was interpreted in relation to the index test

Yes: there is an explicit statement that the index test was interpreted blinded to the reference standard

No: there is an explicit statement that the index test was not interpreted blinded to the results of the reference standard Unclear: there is no statement specifically describing how the index test was interpreted in relation to the reference standard

Yes: there is an explicit statement that the same clinical information was available to those interpreting the index test and reference standard as would be available in routine clinical practice No: there is an explicit statement that clinical information was not made available to those interpreting the index test or reference interpreted blinded to the results of the index test 
standard

Unclear: there is no statement to this effect

10. Were uninterpretable or intermediate test results reported?

Yes: uninterpretable index test results are reported and explained No: if it is explicitly stated or if it is clear from the analysis that there were unreported intermediate or uninterpretable index tests results that were not explained by the authors

Unclear: it is not clear if there were intermediate or uninterpretable index test results and there is no mention of intermediate or uninterpretable results in the text

11. Were withdrawals from the study explained?

Yes: the authors clearly explain why participants withdrew from the study, if there is an explicit statement that there were no withdrawals, or if all patients can be clearly accounted for in the paper No: if it is clear that patients did withdraw but the authors provide no explanation as to why this occurred

Unclear: it is impossible to tell whether patients withdrew from the study

12. Were those interpreting the index test of an appropriate level of training?

Yes: there is a clear statement that an 'expert' (a subspeciality neuroradiologist) or an 'experienced' (defined as $\geq 5$ years of practice at a consultant level or equivalent) radiologist interpreted the index test

No: there is an explicit statement that someone other than a neuroradiologist or an experienced radiologist interpreted the index test results

Unclear: there is no statement describing the background of those who interpreted the index test results or, if a radiologist other than a neuroradiologist interpreted the index test, their years of experience are not provided

\section{CONTRIBUTIONSOFAUTHORS}

CBJ and RA-SS conceived and designed the review. CBJ, PMW, and RA-SS designed the data collection sheet and the search strategies. CBJ searched all databases and screened the search results. $\mathrm{CBJ}$ organised the retrieval of the papers. Two review authors (CBJ and PMW or RA-SS) screened papers against the inclusion criteria, appraised the quality of papers, and extracted data from the papers. CBJ wrote to authors of papers for additional information. CBJ obtained and screened data on unpublished studies. CBJ was responsible for data management for the review and entered data into RevMan 5.2. CBJ, PMW, AK, and RA-SS analysed and interpreted the data. CBJ, PMW, AK, and RA-SS wrote the manuscript, which all authors reviewed. 


\section{DECLARATIONSOF INTEREST}

CBJ, AK, and RA-SS have no known disclosures to report. Siemens Medical, who make all modalities of imaging equipment, are a minor sponsor of an educational neurointerventional meeting co-organised by PMW (all of the grant subsidises the course and no fee goes to the organisers).

\section{SOURCES OF SUPPORT}

\section{Internal sources}

- No sources of support supplied

\section{External sources}

- UK Medical Research Council Senior Clinical Fellowship, UK.

RA-SS is supported by a UK Medical Research Senior Clinical Fellowship

\section{DIFFERENCES BETWEEN PROTOCOLAND REVIEW}

We calculated sensitivity and specificity for the entire population of studies and evaluated only adults (participants $\geq 16$ years of age) in a sensitivity analysis.

We initially planned to conduct a meta-analyses of study-specific pairs of sensitivity and specificity to create a summary ROC curve in the SROC space using the random-effects hierarchical SROC model of Rutter and Gatsonis (Rutter 2001), but instead opted for the bivariate following the review stage (Macaskill 2010).

We used specificity rather than 1-specificity to define the $\mathrm{x}$-axis of the SROC plot.

We used the Metandi package within the Stata Statistical Software version 12.1, rather than Statistical Analysis System (SAS) version 9.2 for Windows, to perform the meta-analysis.

We did not investigate heterogeneity or publication bias because of too few studies (Deeks 2005).

\section{INDEX TERMS}

\section{Medical Subject Headings (MeSH)}

${ }^{*}$ Magnetic Resonance Angiography; ${ }^{*}$ Tomography, X-Ray Computed; Cerebral Angiography [*methods]; Cerebral Hemorrhage [*etiology]; Intracranial Arteriovenous Malformations [*complications; diagnosis]; Randomized Controlled Trials as Topic; Sensitivity and Specificity

\section{MeSH check words}

Adolescent; Adult; Female; Humans; Male; Middle Aged 